\title{
Structural relationships and theoretical study of the free energies of electron transfer, electrochemical properties, and electron transfer kinetic of cephalosporin antibiotics derivatives with fullerenes in nanostructure of $[R] \cdot C_{n}(R=$ cefadroxil, cefepime, cephalexin, cefotaxime, cefoperazone and ceftriaxone) supramolecular complexes
}

\author{
Avat Arman Taherpour • Doreena Narian • \\ Arezou Taherpour \\ Received: 11 September 2014/Accepted: 11 December 2014/Published online: 10 January 2015 \\ (C) The Author(s) 2014. This article is published with open access at Springerlink.com
}

\begin{abstract}
Various empty carbon fullerenes $\left(\mathrm{C}_{n}\right)$ with different carbon atoms have been obtained and investigated. Cephalosporin antibiotics and its derivatives have important medicinal properties. The $\beta$-lactam class of antibiotics has a broad spectrum of antimicrobial properties. Their antibacterial and pharmacokinetic properties have wide therapeutic applications. Topological indices have been successfully used to construct effective and useful mathematical methods to establish clear relationships between structural data and the physical properties of these materials. In this study, the number of carbon atoms in fullerenes was used as an index to establish a relationship between the structures of cefadroxil, cefepime, cephalexin, cefotaxime, cefoperazone and ceftriaxone ( $\beta$-lactam antibiotics) and fullerenes $\left(\mathrm{C}_{n}, n=60,70,76,82\right.$ and 86), which create [cefadroxil] $\cdot \mathrm{C}_{n}$, [cefepime] $\cdot \mathrm{C}_{n}$, [cephalexin] $\cdot \mathrm{C}_{n}$, [cefotaxime] $\cdot \mathrm{C}_{n}$, [cefoperazone] $\cdot \mathrm{C}_{n}$ and [ceftriaxone $] \cdot \mathrm{C}_{n}$. The relationship between the number of
\end{abstract}

A. A. Taherpour $(\bowtie)$

Department of Organic Chemistry, Faculty of Chemistry, Razi University, P.O. Box:67149-67346, Kermanshah, Iran e-mail: avatarman.taherpour@gmail.com

\section{A. A. Taherpour}

Medical Biology Research Center, Kermanshah University

of Medical Sciences, Kermanshah, Iran

\section{Narian}

Chemistry Department, Faculty of Science, Islamic Azad University, Arak Branch, P.O. Box 38135-567, Arak, Iran

\section{A. Taherpour}

Department of Microbiology, Kurdistan University of Medical

Sciences, Sanandaj, Iran fullerene carbon atoms and the free energies of electron transfer $\left(\Delta G_{\text {et(1) }}-\Delta G_{\text {et(4) }}\right)$ are assessed using the RehmWeller equation for A-1 to A-5, B1 to B-5, C-1 to C-5, D-1 to D-5, E-1 to E-5 and F-1 to F-5 of the supramolecular complexes $[\mathrm{R}] \cdot \mathrm{C}_{n}$ (where $\mathrm{R}=$ cefadroxil, cefepime, cephalexin, cefotaxime, cefoperazone and ceftriaxone) complexes. The calculations are presented for the four reduction potentials ( ${ }^{\text {Red. }} E_{1}-{ }^{\text {Red. }} E_{4}$ ) of fullerenes $\mathrm{C}_{n}$. The results were used to calculate the four free energies of electron transfer $\left(\Delta G_{\text {et(1) }}-\Delta G_{\text {et(4) }}\right)$ of the cephalosporinfullerene supramolecular complexes A-1 to A-5, B1 to B-5, C-1 to C-5, D-1 to D-5, E-1 to E-5 and F-1 to F-5 for fullerenes $\mathrm{C}_{60}-\mathrm{C}_{120}$. The free energies of activation for electron transfer, $\Delta G_{\mathrm{et}(n)}^{\#}(n=1-4)$ were also calculated for these complexes in accordance with the Marcus theory. In this study, was presented the calculated wavelengths $\left(\lambda_{(n)}\right.$; $n=1-4$; in $\mathrm{nm}$ ) of the photoelectron transfer process as well in the nanostructure complexes.

Keywords Fullerenes - Cephalosporin antibiotics . Rehm-Weller equation - Free energy of electron transfer . Electron transfer properties - Activated free energies of electron transfer · Marcus theory · Planck's equation · Molecular modeling

\section{Introduction}

Developments in nanoscience and nanotechnology have opened the field to tremendous theoretical and experimental advances in various fields, including biomedical sciences [1-10]. The pharmacokinetic properties of 
cephalosporin antibiotics are nearly identical [11-13]. Cephalosporins consist of a fused $\beta$-lactam- $\Delta^{3}$-dihydrothiazine two-ring system known as 7-aminocephalosporanic acid (7-ACA) and vary in their side chain substituents [11]. Cephalosporin derivatives vary in their resistance to $\beta$-lactamases. Despite relatively extensive knowledge of these drugs, their qualitative and quantitative analyses still give rise to many problems. These difficulties are due to the chemical instability of the common $\beta$-lactam nucleus and minor differences in the chemical structures of the analogs. These structures are classified into four generations based on their resistance to $\beta$-lactamase degradation. Cephalosporins have an added advantage in that the penicillin-allergic patients can be treated with these antibiotics [11-14]. Here, cefadroxil (1, first class), cefepime (2, fourth class), cephalexin ( 3 , first class), cefotaxime ( 4 , third class), cefoperazone (5, third class) and ceftriaxone (6, third class) were selected for the aims and viewpoints of this study.

Cefadroxil is a broad-spectrum bactericidal antibiotic of the cephalosporin type and is effective to treat Grampositive and Gram-negative bacterial infections [15]. Cefadroxil is a first-generation cephalosporin antibacterial drug that is a para-hydroxy derivative of cephalexin, and it has been used similarly in the treatment of mild to moderate susceptible infections, such as the bacterium Streptococcus pyogenes, which causes strep throat. Cefadroxil is used as an antibiotic prophylaxis before dental procedures and can be used for treating infected wounds on animals [15].

Cefepime is a fourth-generation cephalosporin antibiotic developed in 1994. Cefepime has an extended spectrum of activity against Gram-positive and Gram-negative bacteria [15-18]. The combination of the syn-configuration of the methoxyimino moiety and the aminothiazolyl moiety confers extra stability to $\beta$-lactamase enzymes produced by many bacteria. These factors increase the activity of cefepime against otherwise resistant organisms, including Pseudomonas aeruginosa and Staphylococcus aureus [1518].

Cephalexin is a first-generation cephalosporin antibiotic, introduced in 1967 by Eli Lilly and Company [19], and it has similar antimicrobial spectrum to the intravenous agents such as cefalotin and cefazolin. Cephalexin treats urinary tract infections, respiratory tract infections and skin and soft tissue infections. Cephalexin has been used to treat acne, and it is a useful alternative to penicillin derivatives in patients with penicillin hypersensitivity. Cephalexin and other first-generation cephalosporins are known to have a modest cross-allergy in patients with penicillin hypersensitivity $[11-15,19]$.

Cefotaxime is a third-generation cephalosporin antibiotic. Like other third-generation cephalosporins, Cefotaxime has a broad spectrum of activity against Gram-positive and Gram-negative bacteria [20]. The stability of the $\beta$-lactamases increases the activity of cefotaxime against otherwise resistant Gram-negative organisms [20]. Cefotaxime is used to treat infections of the respiratory tract, skin, bones, joints, urogenital system, meningitis and septicemia. Cefotaxime is active against penicillin-resistant strains of Streptococcus pneumoniae and has modest activity against the anaerobic bacteria Bacteroides fragilis. Cefotaxime, like other $\beta$-lactam antibiotics, blocks the division of bacteria (including cyanobacteria), the division of cyanelles (the photosynthetic organelles of the glaucophytes) and the division of chloroplasts in bryophytes [11-13, 20].

Cefoperazone is a third-generation cephalosporin antibiotic, marketed by Pfizer, and it is one of the few cephalosporin antibiotics effective in treating Pseudomonas bacterial infections which are otherwise resistant to these antibiotics [11-13, 21]. Cefoperazone exerts its bactericidal effect by inhibiting bacterial cell wall synthesis, and sulbactam acts as a $\beta$-lactamase inhibitor to increase the antibacterial activity of cefoperazone against $\beta$-lactamaseproducing organisms $[11-13,21]$. Cefoperazone contains an $N$-methylthiotetrazole (NMTT) side chain. As the antibiotic is broken down in the body, free NMTT is released, which can cause hypoprothrombinemia (likely due to the inhibition of the enzyme vitamin $\mathrm{K}$ epoxide reductase) and a reaction with ethanol similar to that produced by disulfiram (Antabuse) due to inhibition of aldehyde dehydrogenase [11-13, 21].

Ceftriaxone is a third-generation cephalosporin antibiotic. Like other third-generation cephalosporins, ceftriaxone has a broad spectrum of activity against Gram-positive and Gram-negative bacteria. In most cases, ceftriaxone is considered to be equivalent to cefotaxime in terms of safety and efficacy $[11-15,22]$. Stability to $\beta$-lactamases increases the activity of ceftriaxone against otherwise resistant Gram-negative bacteria [11-15, 22]. Ceftriaxone has also been investigated for efficacy in preventing relapse to cocaine addiction [15]. Ceftriaxone is often used (in combination, but not directly, with macrolide and/or aminoglycoside antibiotics) for the treatment of communityacquired or mild to moderate health care-associated pneumonia. Ceftriaxone is a choice drug for the treatment of bacterial meningitis [11-15, 22].

The potential applications and physicochemical properties of fullerenes have been investigated. Various empty carbon fullerenes with different " $n$ " numbers, such as $\mathrm{C}_{60}$, $\mathrm{C}_{70}, \mathrm{C}_{76}, \mathrm{C}_{82}$ and $\mathrm{C}_{86}$, have been obtained. The chemical, physical and mechanical properties of empty, exo- and endo-hedral fullerenes have been the subject of many studies [23-41]. The compressive mechanical properties of fullerene molecules $\mathrm{C}_{n}(n=20,60,80$ and 180) were investigated and discussed in detail using a quantum 
molecular dynamics (QMD) technique [25-41]. The unique stability of molecular allotropes, such as $\mathrm{C}_{60}$ and $\mathrm{C}_{70}$, was demonstrated in 1985 [23, 25]. This event led to the discovery of a whole new set of carbon-based substances known as fullerenes.

The electrochemical properties of the $\mathrm{C}_{60}$ have been studied when these materials became available in macroscopic quantities [26-31]. In 1990, Haufler et al. [32] demonstrated that $\mathrm{CH}_{2} \mathrm{Cl}_{2}$ electrochemically reduces $\mathrm{C}_{60}$ to $\mathrm{C}_{60}^{1-}$ and $\mathrm{C}_{60}^{2-}$. Xie et al. [33] cathodically reduced $\mathrm{C}_{60}$ in six reversible one-electron steps for $-0.97 \mathrm{~V}$ vs. $\mathrm{Fc} / \mathrm{Fc}^{+}$ $(\mathrm{Fc}=$ ferrocene). This result, along with the inability to perform anodic electrochemistry on fullerenes, revealed the electronic structure of fullerenes, the LUMO orbitals of $\mathrm{C}_{60}$ can accept up to six electrons to form $\mathrm{C}_{60}^{6-}$, but the position of the HOMO orbitals does not allow for hole-doping under the usual reported electrochemical conditions. Jehoulet et al. [34] reported on the irreversible electrochemical and structural reorganization of solid fullerenes in acetonitrile. Janda et al. [35] improved upon the experimental conditions by investigating highly organized $\mathrm{C}_{60}$ films on highly oriented pyrolytic graphite in an aqueous medium. The reduction of these films induces a morphological change; they re-structure into conductive nano-clusters of $\sim 100 \mathrm{~nm}$ in diameter $[35,36]$.

Graph theory has been a useful tool in assessing the quantitative structural activity relationship and quantitative structural property relationship [42-53]. A lot of studies in different areas have used topological indices [42-50]. Any extrapolation of results from one compound to other compounds must take into account considerations based on a QSAR study, which depends on how close the chemical properties are of the compounds in question. Effective mathematical methods must be employed to make good correlations between several properties of chemicals. Several applications of the indices have been reported [4253]. The number of carbon atoms in the various fullerene structures was determined with these applications.

The Marcus theory builds on the Arrhenius equation for the rates of chemical reactions in two ways. A formula for the pre-exponential factor in the Arrhenius equation, based on the electronic coupling between the initial and final state of the electron transfer reaction (i.e., the overlap of the electronic wave functions of the two states), is provided. A formula for the activation energy, based on a parameter called the reorganization energy, and the Gibbs free energy is given. Although electrons are commonly described as residing in electron bands in bulk materials and electron orbitals in molecules, the following description will be described in molecular terms. When a photon excites a molecule, an electron in a ground state orbital can be excited to a higher energy orbital. This excited state leaves a vacancy in a ground state orbital that can be filled by an electron donor. An electron is produced in a high-energy orbital and can be donated to an electron acceptor. Photo-induced electron transfer is an electron transfer that occurs when certain photoactive materials interact with light, including semiconductors that can be photo-activated, such as many solar cells, biological systems like those used in photosynthesis, and small molecules with suitable absorptions and redox states [54-62].

The electron transfer process is one of the most important chemical processes in nature and plays a central role in many biological, physical and chemical systems. Solidstate electronics depends on the control of the electron transfer in semiconductors and the new area of molecular electronics depends critically on the understanding and control of the transfer of electrons between molecules and nanostructures. The other reason to study electron transfer is that it is a simple kind of chemical reaction, and by understanding it, one can gain insight into other kinds of chemistry and biochemistry. After all, what is important is the chemistry of the transfer of electrons from one place to another [55-62].

The free energy of electron transfer $\Delta G_{\text {et }}$ is the difference between the reactants on the left and the products on the right, and $\Delta G_{\mathrm{et}}^{\#}$ is the activation energy [55-62].

The Marcus theory is currently the dominant theory of ET process in chemistry. The Marcus theory has widely accepted because it makes surprising predictions about electron transfer rates that have been supported experimentally over the last several decades. The most significant prediction is that the rate of electron transfer will increase as the electron transfer reaction becomes more exergonic, but only to a point [55-62]. Electron transfer happens in the chemical reactions. Is it any particular model and mechanism that works well in this case in analogy with many such models and mechanisms that work fine in material sciences [63-69].

Here, were calculated the first to fourth activation free energies of electron transfer $\Delta G_{\mathrm{et}(\mathrm{n})}^{\#}(n=1-4)$ and the kinetic rate constants of the electron transfers $k_{\text {et }}(n=1-4)$ using the Marcus theory and the equations on the basis of the first to fourth reduction potentials $\left({ }^{\text {Red. }} E_{1}{ }^{-}{ }^{\text {Red. }} E_{4}\right.$ ) of fullerenes $\mathrm{C}_{n}(n=60,70,76,82$ and 86$)$ for the predicted supramolecular complexes [cefadroxil]. $\mathrm{C}_{n} \mathbf{7 - 1 1}$ and 3740; [cefepime] $\cdot \mathrm{C}_{n}, \mathbf{1 2}-16$ and 41-44; [cephalexin] $\mathrm{C}_{n}, 17$ 21 and 45-48; [cefotaxime] $\mathrm{C}_{\boldsymbol{n}}, \mathbf{2 2 - 2 6}$ and 49-52; [cefoperazone] $\cdot \mathrm{C}_{n}, \mathbf{2 7}-\mathbf{3 1}$ and $53-56$ and [ceftriaxone] $\mathrm{C}_{n}, \mathbf{3 2}$ 36 and 57-60 (supramolecular complexes 7-60). See Eqs. 2 and 3, Tables 6, 7, 8, 9 and 10 and Fig. 3.

This study elaborates upon the relationship between the number of carbon atoms and the four free energies of 
electron transfer $\left(\Delta G_{\mathrm{et}(1)}-\Delta G_{\mathrm{et}(4)}\right)$ of fullerenes $\mathrm{C}_{n}(n=60$, $70,76,82$ and 86) with cefadroxil, cefepime, cephalexin, cefotaxime, cefoperazone and ceftriaxone on the basis of the four reduction potentials ( ${ }^{\text {Red. }} E_{1}{ }^{\text {Red. }} E_{4}$ ) of the fullerenes.

The relationships are assessed by applying the RehmWeller equation [54] to create [cefadroxil]. $\mathrm{C}_{n}, \mathbf{A - 1}$ to A-5; [cefepime]. $\mathrm{C}_{n}, \mathbf{B}-\mathbf{1}$ to B-5; [cephalexin]. $\mathrm{C}_{n}, \mathbf{C}-\mathbf{1}$ to $\mathbf{C - 5}$; [cefotaxime] $\cdot \mathrm{C}_{n}, \mathbf{D - 1}$ to D-5; [cefoperazone] $\mathrm{C}_{n}, \mathbf{E - 1}$ to $\mathbf{E}-$ 5 and [ceftriaxone] $\mathbf{C}_{n}, \mathbf{F}-\mathbf{1}$ to $\mathbf{F - 5}$. The results were extended to calculate the four free energies of electron transfer $\left(\Delta G_{\text {et(1) }}-\Delta G_{\text {et(4) }}\right)$ of other supramolecular complexes of cefadroxil, cefepime, cephalexin, cefotaxime, cefoperazone and ceftriaxone as a class of electron-transfers with fullerenes $\mathrm{C}_{60}-\mathrm{C}_{300}$ ([cephalosporin antibiotics]. $\mathrm{C}_{n}$ complexes: [cefadroxil] $\cdot \mathrm{C}_{n} \quad \mathbf{7 - 1 1}$ and 37-40; [cefepime] $\cdot \mathrm{C}_{n}, \mathbf{1 2 - 1 6}$ and 41-44; [cephalexin] $\cdot \mathrm{C}_{n}, 17-21$ and 45-48; [cefotaxime] $\mathrm{C}_{n}, \mathbf{2 2 - 2 6}$ and 49-52; [cefoperazone] $\cdot \mathrm{C}_{n}, \mathbf{2 7 - 3 1}$ and 53-56 and [ceftriaxone] $\mathrm{C}_{n}, \mathbf{3 2 - 3 6}$ and 57-60, supramolecular complexes 7-121). This study calculated the four free energies of electron transfer $\left(\Delta G_{\mathrm{et}(1)}-\Delta G_{\mathrm{et}(4)}\right)$ of $\mathbf{A}-1$ to $\mathbf{A - 1 9}, \mathbf{B}-1$ to $\mathbf{B}-19, \mathbf{C}-1$ to $\mathbf{C - 1 9}$, D-1 to D-19, E-1 to E-19 and F-1 to F-19 (see Eqs. 1-23, Tables 1, 2, 3, 4, 5; Figs. 1, 2).

Also, in this study, were calculated the activate free energies of electron transfer and the maximum wave length of the electron transfers, $\Delta G_{\text {et }(n)}^{\#}$ and $\lambda_{\text {et }}$, respectively, using Marcus theory and the equations on the basis of the oxidation potentials of fullerenes $\mathrm{C}_{n}(n=60,70,76,82$ and 86) to predict the data of the electron transfer process between the antibiotic compounds (cefadroxil, cefepime, cephalexin, cefotaxime, cefoperazone and ceftriaxone) and the fullerenes.
One of the aspects in this study was the relationship between the number of carbon atoms in the fullerenes $\mathrm{C}_{n}$ $\left(\mathrm{C}_{60}, \mathrm{C}_{70}, \mathrm{C}_{76}, \mathrm{C}_{82}\right.$ and $\left.\mathrm{C}_{86}\right)$ and the data values on the electron transfer $\left(\Delta G_{\mathrm{et}}\right.$, in $\left.\mathrm{kcal} \mathrm{mol}^{-1}\right)$ between the antibiotic compounds (cefadroxil, cefepime, cephalexin, cefotaxime, cefoperazone and ceftriaxone) with the fullerenes.

One of the other aspects of this study was the investigation of the photo-electron transfer process to find more medicinal activity conditions and properties for the antibiotics 1-6 in the presence of the selected fullerenes by performing the supramolecular complexes [antibiotics 1-6]. $\mathrm{C}_{n}$.

\section{Graphing and mathematical method}

For the entire diagram operations were applied Microsoft Office Excel-2003. To investigate several properties of the fullerenes can be utilized the number of carbon atoms of the fullerenes. The values were applied to calculate $\Delta G_{\text {et(1) }}-\Delta G_{\text {et(4) }}$, according to the Rehm-Weller equation for the complexes [cefadroxil] $\cdot \mathrm{C}_{n} \mathbf{7 - 1 1}$ and 37-40; [cefepime] $\cdot \mathrm{C}_{n}, 12-16$ and 41-44; [cephalexin] $\mathrm{C}_{n}, 17-21$ and 45-48; [cefotaxime] $\mathrm{C}_{n}, \mathbf{2 2 - 2 6}$ and 49-52; [cefoperazone] $\cdot \mathrm{C}_{n}, 27-31$ and 53-56 and [ceftriaxone] $\cdot \mathrm{C}_{n}, 32-36$ and 57-60 (supramolecular complexes 7-60).

The linear multiple linear regressions and nonlinear models have utilized in this study. The Eqs. 1 and 4-23 were applied to calculate the values of $\Delta G_{\mathrm{et}(1)}-\Delta G_{\mathrm{et}(4)}$ for complexes that have not been reported in the literature. The best results and equations to extend the physicochemical data have chosen $[48,53]$.

Table 1 The data values on the Cefadroxil 1 and the values of the 4 free energies of electron transfer $\left(\Delta G_{\text {et }}\right)$, in kcal mol ${ }^{-1}$, between Cefadroxil and $\mathrm{C}_{n}$ (as [Cefadroxil]. $\mathrm{C}_{n} ; \mathbf{7 - 1 1}$ and 37-40) supramolecular complexes

\begin{tabular}{|c|c|c|c|c|c|c|}
\hline \multirow[t]{2}{*}{ No. } & \multirow[t]{2}{*}{ Row } & \multirow[t]{2}{*}{ Formula of [Cefadroxil] $\cdot \mathrm{C}_{n}$} & \multicolumn{4}{|c|}{$\left(\Delta G_{\text {et }}\right)$ in $\mathrm{kcal} \mathrm{mol}^{-1}$ [Cefadroxil] $\cdot \mathrm{C}_{n}$} \\
\hline & & & $\Delta G_{\mathrm{et}(1)}$ & $\Delta G_{\mathrm{et}(2)}$ & $\Delta G_{\mathrm{et}(3)}$ & $\Delta G_{\mathrm{et}(4)}$ \\
\hline 7 & A-1 & [Cefadroxil]. $\mathrm{C}_{60}$ & 51.70 & 60.80 & 71.08 & 81.71 \\
\hline 8 & A-2 & [Cefadroxil].C $\mathrm{C}_{70}$ & 50.35 & 59.40 & 67.93 & 77.80 \\
\hline 9 & A-3 & [Cefadroxil]. $\mathrm{C}_{76}$ & 47.28 & 55.87 & 65.79 & 75.09 \\
\hline 10 & A-4 & [Cefadroxil]. $\mathrm{C}_{82}$ & 42.53 & 50.33 & 63.48 & 72.11 \\
\hline 11 & A-5 & [Cefadroxil]. $\mathrm{C}_{86}$ & 38.41 & 45.51 & 61.84 & 69.96 \\
\hline 37 & A-6 & [Cefadroxil].C $\mathrm{C}_{78}$ & 45.89 & 54.25 & 65.04 & 74.13 \\
\hline 38 & A-7 & [Cefadroxil]. $\mathrm{C}_{84}$ & 40.56 & 48.03 & 62.67 & 71.05 \\
\hline 39 & A-8 & [Cefadroxil]. $\mathrm{C}_{96}$ & 24.84 & 29.55 & 57.38 & 64.07 \\
\hline 40 & A-9 & [Cefadroxil]. $\mathrm{C}_{120}$ & -26.90 & -31.60 & 44.61 & 46.81 \\
\hline
\end{tabular}

The data of $\Delta G_{\mathrm{et}(n)}(n=1-4)$ were predicted by using Eqs. 4-7, and those in parentheses were calculated by the Rehm-Weller equation (Eq. 1) The data of the free energy of electron transfer $\left(\Delta G_{\mathrm{et}(1)}-\Delta G_{\mathrm{et}(4)}\right)$ for [Cefadroxil]. $\mathrm{C}_{n}$ compounds had not been previously reported 
Table 2 The data values on the Cefepime 2 and the values of the 4 free energies of electron transfer $\left(\Delta G_{\text {et }}\right)$, in kcal mol ${ }^{-1}$, between Cefepime with $\mathrm{C}_{n}$ (as [Cefepime] $\mathrm{C}_{n}, \mathbf{1 2 - 1 6}$ and $\mathbf{4 1 - 4 4}$ ) supramolecular complexes

\begin{tabular}{|c|c|c|c|c|c|c|}
\hline \multirow[t]{2}{*}{ No. } & \multirow[t]{2}{*}{ Row } & \multirow[t]{2}{*}{ Formula of [Cefepime] $\cdot \mathrm{C}_{n}$} & \multicolumn{4}{|c|}{$\left(\Delta G_{\mathrm{et}}\right)$ in $\mathrm{kcal} \mathrm{mol}{ }^{-1}[$ Cefepime $] \cdot \mathrm{C}_{n}$} \\
\hline & & & $\Delta G_{\mathrm{et}(1)}$ & $\Delta G_{\mathrm{et}(2)}$ & $\Delta G_{\mathrm{et}(3)}$ & $\Delta G_{\mathrm{et}(4)}$ \\
\hline 12 & B-1 & {$\left[\right.$ Cefepime]. $\mathrm{C}_{60}$} & 50.80 & 59.90 & 70.18 & 80.81 \\
\hline 13 & B-2 & {$\left[\right.$ Cefepime]. $\mathrm{C}_{70}$} & 49.45 & 58.50 & 67.03 & 76.90 \\
\hline 14 & B-3 & {$\left[\right.$ Cefepime].C $\mathrm{C}_{76}$} & 46.38 & 54.97 & 64.89 & 74.19 \\
\hline 15 & B-4 & [Cefepime]. $C_{82}$ & 41.63 & 49.43 & 62.58 & 71.21 \\
\hline 16 & B-5 & [Cefepime].C $C_{86}$ & 37.51 & 44.61 & 60.94 & 69.06 \\
\hline 41 & B-6 & [Cefepime].C $C_{78}$ & 44.99 & 53.35 & 64.14 & 73.23 \\
\hline 42 & B-7 & [Cefepime]. $C_{84}$ & 39.66 & 47.13 & 61.77 & 70.15 \\
\hline 43 & B-8 & [Cefepime].C $\mathrm{C}_{96}$ & 23.94 & 28.65 & 56.48 & 63.17 \\
\hline 44 & B-9 & [Cefepime].C $\mathrm{C}_{120}$ & -27.80 & -32.50 & 43.71 & 45.91 \\
\hline
\end{tabular}

The data of $\Delta G_{\mathrm{et}(\mathrm{n})}(n=1-4)$ were predicted by using Eqs. 8-11, and those in parentheses were calculated by the Rehm-Weller equation (Eq. 1) The data of the free energy of electron transfer $\left(\Delta G_{\mathrm{et}(1)}\right.$ to $\left.\Delta G_{\mathrm{et}(4)}\right)$ for [Cefepime] $\mathrm{C}_{n}$ compounds had not been previously reported

Table 3 The data values on the Cephalexin 3 and the values of the 4 free energies of electron transfer $\left(\Delta G_{\mathrm{et}}\right)$, in $\mathrm{kcal}$ mol ${ }^{-1}$, between Cephalexin with $\mathrm{C}_{n}$ (as [Cephalexin] $\mathrm{C}_{n}, \mathbf{1 7 - 2 1}$ and 45-48) supramolecular complexes

\begin{tabular}{|c|c|c|c|c|c|c|}
\hline \multirow[t]{2}{*}{ No. } & \multirow[t]{2}{*}{ Row } & \multirow[t]{2}{*}{ Formula of [Cephalexin] $\cdot \mathrm{C}_{n}$} & \multicolumn{4}{|c|}{$\left(\Delta G_{\text {et }}\right)$ in $\mathrm{kcal} \mathrm{mol}^{-1}\left[\right.$ Cephalexin] $\cdot \mathrm{C}_{n}$} \\
\hline & & & $\Delta \mathrm{G}_{\mathrm{et}(1)}$ & $\Delta G_{\mathrm{et}(2)}$ & $\Delta G_{\mathrm{et}(3)}$ & $\Delta G_{\mathrm{et}(4)}$ \\
\hline 17 & $\mathrm{C}-1$ & [Cephalexin]. $\mathrm{C}_{60}$ & 38.90 & 47.14 & 57.96 & 68.61 \\
\hline 18 & $\mathrm{C}-2$ & [Cephalexin]. $\mathrm{C}_{70}$ & 37.35 & 45.61 & 54.82 & 64.70 \\
\hline 19 & $\mathrm{C}-3$ & [Cephalexin]. $\mathrm{C}_{76}$ & 34.26 & 41.99 & 52.69 & 61.99 \\
\hline 20 & $\mathrm{C}-4$ & [Cephalexin]. $\mathrm{C}_{82}$ & 29.55 & 36.36 & 50.37 & 59.01 \\
\hline 21 & $\mathrm{C}-5$ & [Cephalexin]. $\mathrm{C}_{86}$ & 25.51 & 31.47 & 48.72 & 56.86 \\
\hline 45 & C-6 & [Cephalexin]. $\mathrm{C}_{78}$ & 32.87 & 40.34 & 51.94 & 61.03 \\
\hline 46 & $\mathrm{C}-7$ & [Cephalexin]. $\mathrm{C}_{84}$ & 27.62 & 34.03 & 49.56 & 57.95 \\
\hline 47 & $\mathrm{C}-8$ & [Cephalexin].C96 & 12.26 & 15.33 & 44.23 & 50.97 \\
\hline 48 & C-9 & [Cephalexin]. $\mathrm{C}_{120}$ & -37.90 & -46.34 & 31.32 & 33.71 \\
\hline
\end{tabular}

The data of $\Delta G_{\mathrm{et}(n)}(n=1-4)$ were predicted by using Eqs. 12-15, and those in parentheses were calculated by the Rehm-Weller equation (Eq. 1)

The data of the free energy of electron transfer $\left(\Delta G_{\mathrm{et}(1)}\right.$ to $\left.\Delta G_{\mathrm{et}(4)}\right)$ for [Cephalexin] $\mathrm{C}_{n}$ compounds had not been previously reported

The free energy changes between an electron donor $(D)$ and an acceptor $(A)$ for the electron transfer (ET) were estimates by the Rehm-Weller equation:

$\Delta G^{o}=\mathrm{e}\left[E_{D}^{o}-E_{A}^{o}\right]-\Delta E^{*}+\omega_{1}$

In this equation, " $e$ " is the unit electrical charge. The reduction potentials of the electron donor and acceptor were introduced as $E_{\mathrm{D}}^{0}$ and $E_{\mathrm{A}}^{0}$, respectively. The value of $\Delta E^{*}$ is the energy of the singlet or triplet excited state. The work required to bring the donor and acceptor to within the electron transfer (ET) distance has determined by $\omega_{1}$. The work term in this expression is zero if an electrostatic complex forms before the ET-process [54].

The Marcus theory of ET-process suggests rather weak electronic coupling between the initial (LE) and final (ET), locally excited and electron transfer states, respectively.
The transition state (TS) is near to the crossing point of the LE and ET terms. The value of the ET rate constant is controlled by the $\Delta G_{\text {et }}^{\#}$, which is a function of the reorganization energy $(\mathrm{RE} ; 1 / 4)$ and the ET driving force, $\Delta G_{\mathrm{et}}$ : $\Delta G_{\mathrm{et}}^{\#}=(l / 4)\left(1+\Delta G_{\mathrm{et}} / l\right)^{2}$,

The reorganization energy ( $\mathrm{RE}$ ) has defined as the energy required reorganizing the system structure from the initial to final coordinates without changing the electronic state. The RE was found to be in the range $0.1-0.3 \mathrm{eV}$ for organic molecules. Here, the minimum amount of RE was used [55-62].

The Planck's formula has applied to calculate the maximum wavelengths $\left(\lambda_{(n)}\right)$ of the electromagnetic photon for the ET-process in the selected nanostructure complexes: 
Table 4 The data values on the Dodecahydro Cefotaxime 4 and the values of the 4 free energies of electron transfer $\left(\Delta G_{\mathrm{et}}\right)$, in kcal mol ${ }^{-1}$, between Cefotaxime with $\mathrm{C}_{n}$ (as [Cefotaxime] $\mathrm{C}_{n}, \mathbf{2 2 - 2 6}$ and 49-52) supramolecular complexes

\begin{tabular}{|c|c|c|c|c|c|c|}
\hline \multirow[t]{2}{*}{ No. } & \multirow[t]{2}{*}{ Row } & \multirow[t]{2}{*}{ Formula of [Cefotaxime] $\cdot \mathrm{C}_{n}$} & \multicolumn{4}{|c|}{$\left(\Delta G_{\mathrm{et}}\right)$ in kcal mol${ }^{-1}[$ Cefotaxime $] \cdot \mathrm{C}_{n}$} \\
\hline & & & $\Delta G_{\mathrm{et}(1)}$ & $\Delta G_{\mathrm{et}(2)}$ & $\Delta G_{\mathrm{et}(3)}$ & $\Delta G_{\mathrm{et}(4)}$ \\
\hline 22 & D-1 & {$[$ Cefotaxime $] . \mathrm{C}_{60}$} & 48.80 & 57.80 & 68.09 & 78.70 \\
\hline 23 & D-2 & {$[$ Cefotaxime $] . \mathrm{C}_{70}$} & 47.45 & 56.40 & 64.93 & 74.81 \\
\hline 24 & D-3 & {$[$ Cefotaxime $] . \mathrm{C}_{76}$} & 44.38 & 52.87 & 62.80 & 72.10 \\
\hline 25 & D-4 & {$[$ Cefotaxime $] . \mathrm{C}_{82}$} & 39.63 & 47.33 & 60.48 & 69.11 \\
\hline 26 & D-5 & [Cefotaxime]. $\mathrm{C}_{86}$ & 35.51 & 42.51 & 58.84 & 66.97 \\
\hline 49 & D-6 & {$[$ Cefotaxime $] . \mathrm{C}_{78}$} & 42.99 & 51.25 & 62.05 & 71.13 \\
\hline 50 & D-7 & [Cefotaxime]. $\mathrm{C}_{84}$ & 37.66 & 45.03 & 59.67 & 68.06 \\
\hline 51 & D-8 & [Cefotaxime].C 96 & 21.94 & 26.55 & 54.38 & 61.07 \\
\hline 52 & D-9 & [Cefotaxime].C $\mathrm{C}_{120}$ & -29.80 & -34.60 & 68.09 & 43.78 \\
\hline
\end{tabular}

The data of $\Delta \mathrm{G}_{e t(n)}(n=1-4)$ were predicted by using Eqs. 16-19, and those in parentheses were calculated by the Rehm-Weller equation (Eq. 1)

The data of the free energy of electron transfer $\left(\Delta G_{\mathrm{et}(1)}\right.$ to $\left.\Delta G_{\mathrm{et}(4)}\right)$ for [Cefotaxime] $\mathrm{C}_{n}$ compounds had not been previously reported

Table 5 The data values on the CFO 5 and ROC 6 and the values of the 4 free energies of electron transfer $\left(\Delta G_{\mathrm{et}}\right)$, in kcal mol ${ }^{-1}$, between CFO and ROC with $\mathrm{C}_{n}$ (as [CFO] $\cdot \mathrm{C}_{n}, \mathbf{2 7 - 3 1}$ and 53-56 and [ROC] $\cdot \mathrm{C}_{\mathrm{n}}, \mathbf{3 2}-\mathbf{3 6}$ and 57-60) supramolecular complexes

\begin{tabular}{|c|c|c|c|c|c|c|c|c|c|}
\hline \multirow[t]{2}{*}{ No. } & \multirow[t]{2}{*}{ Row } & \multirow[t]{2}{*}{ Formula of $[\mathrm{CFO}] \cdot \mathrm{C}_{n}$} & \multirow[t]{2}{*}{ No. } & \multirow[t]{2}{*}{ Row } & \multirow[t]{2}{*}{ Formula of $[\mathrm{ROC}] \cdot \mathrm{C}_{n}$} & \multicolumn{4}{|c|}{$\left(\Delta G_{\text {et }}\right)$ in $\mathrm{kcal} \mathrm{mol}^{-1}[\mathrm{CFO}$ and $\mathrm{ROC}] \cdot \mathrm{C}_{n}$} \\
\hline & & & & & & $\Delta G_{\mathrm{et}(1)}$ & $\Delta G_{\mathrm{et}(2)}$ & $\Delta G_{\mathrm{et}(3)}$ & $\Delta G_{\mathrm{et}(4)}$ \\
\hline 27 & E-1 & {$[\mathrm{CFO}] . \mathrm{C}_{60}$} & 32 & F-1 & {$[\mathrm{ROC}] . \mathrm{C}_{60}$} & 49.50 & 58.04 & 68.76 & 79.41 \\
\hline 28 & E-2 & {$[\mathrm{CFO}] . \mathrm{C}_{70}$} & 33 & $\mathrm{~F}-2$ & {$[\mathrm{ROC}] \cdot \mathrm{C}_{70}$} & 48.15 & 56.51 & 65.60 & 75.50 \\
\hline 29 & E-3 & {$[\mathrm{CFO}] . \mathrm{C}_{76}$} & 34 & F-3 & {$[\mathrm{ROC}] \cdot \mathrm{C}_{76}$} & 45.08 & 52.89 & 63.47 & 72.79 \\
\hline 30 & E-4 & {$[\mathrm{CFO}] . \mathrm{C}_{82}$} & 35 & F-4 & {$[\mathrm{ROC}] \cdot \mathrm{C}_{82}$} & 40.33 & 47.26 & 61.16 & 69.81 \\
\hline 31 & E-5 & {$[\mathrm{CFO}] . \mathrm{C}_{86}$} & 36 & F-5 & {$[\mathrm{ROC}] \cdot \mathrm{C}_{86}$} & 36.21 & 42.37 & 59.52 & 67.66 \\
\hline 53 & E-6 & {$[\mathrm{CFO}] . \mathrm{C}_{78}$} & 57 & F-6 & {$[\mathrm{ROC}] \cdot \mathrm{C}_{78}$} & 43.69 & 51.24 & 62.72 & 71.83 \\
\hline 54 & E-7 & {$[\mathrm{CFO}] . \mathrm{C}_{84}$} & 58 & F-7 & {$[\mathrm{ROC}] \cdot \mathrm{C}_{84}$} & 38.36 & 44.93 & 60.35 & 68.75 \\
\hline 55 & E-8 & {$[\mathrm{CFO}] . \mathrm{C}_{96}$} & 59 & F-8 & {$[\mathrm{ROC}] . \mathrm{C}_{96}$} & 22.64 & 26.23 & 55.08 & 61.77 \\
\hline 56 & E-9 & {$[\mathrm{CFO}] . \mathrm{C}_{120}$} & 60 & F-9 & {$[\mathrm{ROC}] . \mathrm{C}_{120}$} & -29.10 & -35.44 & 42.41 & 44.51 \\
\hline
\end{tabular}

The data of the free energy of electron transfer $\left(\Delta G_{\mathrm{et}(1)}\right.$ to $\left.\Delta G_{\mathrm{et}(4)}\right)$ for [CFO]. $\mathrm{C}_{n}$ and [ROC] $\cdot \mathrm{C}_{n}$ compounds had not been previously reported The data of $\Delta G_{\operatorname{et}(n)}(n=1-4)$ were predicted by using Eqs. 4-7, and those in parentheses were calculated by the Rehm-Weller equation (Eq. 1)

$\Delta G_{\mathrm{et}}^{\#}=\Delta E=\mathrm{h} \times \mathrm{c} / \lambda_{(n)}$.

In this study, has also used this formula to calculate the activation free energy of the ET-process [63, 69, 70].

\section{Discussion}

Cefadroxil is a first-generation cephalosporin and is effective against Gram-positive cocci. In 2000, the electrooxidation of cefadroxil was investigated by Özkan et al. [71], and they used a glassy carbon electrode (GCE) for cyclic voltammetry (CV) and differential pulse voltammetry (DPV)

Cefepime was studied by electrochemical reduction and oxidation with a carbon electrode in an aqueous buffer solution of $\mathrm{pH}<8.0$ [72]. Electro-analysis of cefalexin was performed in a $0.1 \mathrm{M}$ carbonate buffer ( $\mathrm{pH}$ 9.2) using a boron-doped diamond thin-film electrodes for CV measurements [73].

Cefalexin was measured polarographically in pure form and in pharmaceutical preparations based on the catalytic hydrogen wave observed in the presence of cobalt (II) and the drug at a potential of $-1.47 \mathrm{~V}$ versus SCE [51]. The electro-oxidation of cefalexin at boron-doped diamond electrodes and glassy carbon electrodes was investigated by $\mathrm{CV}$ [75].

In 2009, the electrochemical behavior of cefotaxime was studied using modified carbon paste electrode (Nigam et al. [14]). CV and DPV were used for the estimation of the drug using a modified carbon paste capillary as the working electrode [53]. Voltammograms 


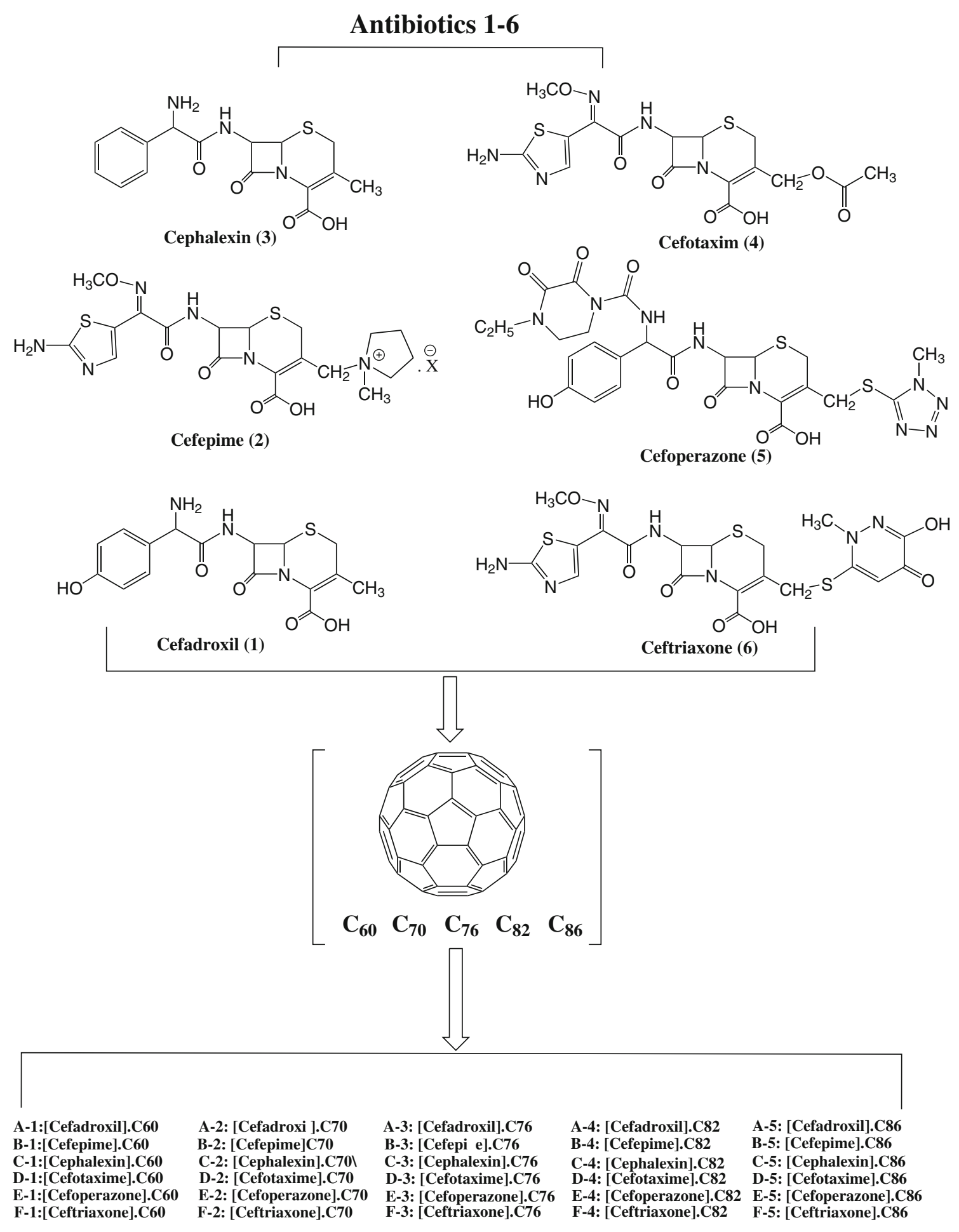

Fig. 1 The conjectured structures of cefadroxil, cefepime, cephalexin, cefotaxime, cefoperazone (CFO) and ceftriaxone (ROC) as well as the fullerenes $\mathrm{C}_{n}(n=60,70,76,82$ and 86), which create [cefadroxil]. $\mathrm{C}_{n}$ A-1 to A-5; [cefepime] $\mathrm{C}_{n}, \mathbf{B}-\mathbf{1}$ to B-5; [cephalexin] $\cdot \mathrm{C}_{n}, \mathbf{C}-1$ to $\mathbf{C - 5}$; [cefotaxime] $\mathrm{C}_{n}, \mathbf{D}-1$ to D-5; [cefoperazone] $\mathrm{C}_{n}, \mathbf{E}-\mathbf{1}$ to $\mathbf{E}-5$ and [ceftriaxone] $\mathrm{C}_{n}, \mathbf{F}-\mathbf{1}$ to $\mathbf{F}-5$ were recorded in a potential window- $0.2-1.1 \mathrm{~V}$ vs. $\mathrm{Ag} /$ $\mathrm{AgCl}$ at various scan rates and DPV with a pulse width $0.05 \mathrm{~s}$ [76].
Various concentrations of cefotaxime from $0.1 \mathrm{mM}$ to 1 $\mathrm{nM}$ were analyzed in water and in acidified human blood samples (pH 2.3) [76]. 


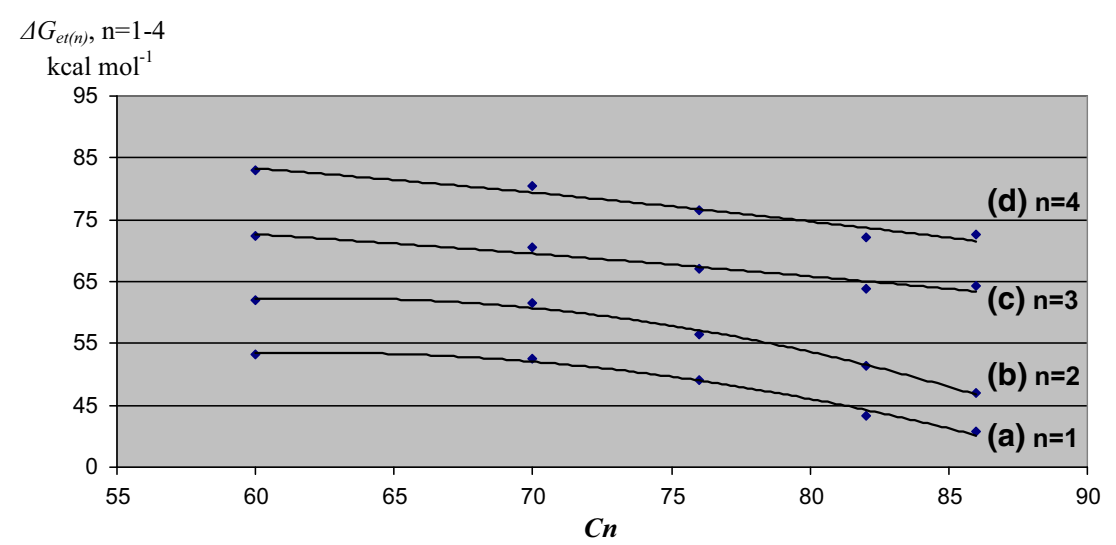

Fig. 2 The relationship between the number of carbon atoms "n" of the fullerenes and the first (a) to fourth (d) of $\left(\Delta G_{\mathrm{et}(n)}, n=1-4\right)$ in ET-process of [Cefadroxil]. $\mathrm{C}_{n}(n=60,70,76,82$ and 86), compounds A-1 to A-5 (7-11). Asterisk the related curves for

Two cephalosporin antibiotic derivatives, cefoperazone and ceftriaxone, were studied with direct current, differential pulse polarography (DPP) and CV methods [77]. The electro-oxidation of both cephalosporin derivatives had studied at the carbon paste electrode (CPE). Both drugs gave rise to one oxidation peak at about $+1.05 \mathrm{~V}$ vs. SCE [77].

The oxidation potentials of cefadroxil, cefepime, cephalexin, cefotaxime, cefoperazone and ceftriaxone, which have been previously reported [71-78] are as follows:

\begin{tabular}{llll}
\hline No. & $\begin{array}{l}\text { Cephalosporin } \\
\text { derivatives }\end{array}$ & $\begin{array}{l}\text { Oxidation potential } \\
\left({ }^{\text {Ox }} E, \text { in volts }\right)\end{array}$ & $\begin{array}{l}\text { Reference } \\
\text { number }\end{array}$ \\
\hline $\mathbf{1}$ & Cefadroxil & +1.15 & {$[71]$} \\
$\mathbf{2}$ & Cefepime & +0.97 & {$[72,73]$} \\
$\mathbf{3}$ & Cephalexin & +0.58 & {$[74,75]$} \\
$\mathbf{4}$ & Cefotaxime & +1.02 & {$[76]$} \\
$\mathbf{5}$ & Cefoperazone & +1.05 & {$[77]$} \\
$\mathbf{6}$ & Ceftriaxone & +1.05 & {$[77]$} \\
\hline
\end{tabular}

The four reported reduction potentials $\left({ }^{\text {Red. }} E_{1}{ }^{-}{ }^{\text {Red. }} E_{4}\right.$ ) of fullerenes $\mathrm{C}_{n}$ are as follows. For $\mathrm{C}_{60}$, the potentials ${ }^{\text {Red. }} E_{1}{ }^{-}{ }^{\text {Red. }} E_{4}$ are $-1.12,-1.50,-1.95$ and $-2.41 \mathrm{~V}$, respectively [79]. The ${ }^{\mathrm{Red}} E_{n}(n=1-4)$ for $\mathrm{C}_{70}$ are -1.09 , $-1.48,-1.87$ and $-2.30 \mathrm{~V}$, respectively [79]. The values of ${ }^{\mathrm{Red}} E_{n}(n=1-4)$ for $\mathrm{C}_{76}$ are $-0.94,-1.26,-1.72$ and $-2.13 \mathrm{~V}$, respectively [79]. The values of ${ }^{\mathrm{Red}} E_{n}(n=1-4)$ for $\mathrm{C}_{82}$ are $-0.69,-1.04,-1.58$ and $-1.94 \mathrm{~V}$, respectively [79]. The ${ }^{\mathrm{Red}} E_{n}(n=1-4)$ for $\mathrm{C}_{86}$ are $-0.58,-0.85$, -1.60 and $-1.96 \mathrm{~V}$, respectively [79]. $\mathrm{C}_{180}$ and $\mathrm{C}_{240}$ were not prepared or isolated along with the fullerenes have listed in Tables 1, 2, 3, 4.
[Cefepime] $\mathbf{C}_{n}$, B-1 to $\mathbf{B - 5}$, [Cephalexin] $\cdot \mathbf{C}_{n}, \mathbf{C}-\mathbf{1}$ to $\mathbf{C - 5}$, [Cefotaxime]@ $\mathrm{C}_{n}$, D-1 to D-5 Cefoperazone]. $\mathrm{C}_{n}, \mathbf{E}-\mathbf{1}$ to E-5 and [Ceftriaxone] $\cdot \mathrm{C}_{n}, \mathbf{F}-\mathbf{1}$ to $\mathbf{F}-\mathbf{5}$ have similar style to Fig. 2(a-d) [Cefadroxil] $\cdot \mathrm{C}_{n}$ A-1 to A-5

Tables 1, 2, 3, 4 and 5 contain a summary of the data. The calculated values for $\mathbf{6 - 1}$ of the four electron transfer free energies $\left(\Delta G_{\mathrm{et}(1)}-\Delta G_{\mathrm{et}(4)}\right.$, in $\left.\mathrm{kcal} \mathrm{mol}^{-1}\right)$ between the cephalosporin antibiotics 1-5 and fullerenes $\mathrm{C}_{n}(n=60$, $70,76,82$ and 86) as [cephalosporin antibiotics] $\mathrm{C}_{n}$ complexes are shown. These values were calculated using the Rehm-Weller equation (Eq. 1). The selected cephalosporin antibiotics (1-5) were used to model the structural relationship between the number of carbon atoms $(n)$ in the selected fullerenes and $\Delta G_{\mathrm{et}(\mathrm{n})}(n=1-4)$. The data of compounds [cefadroxil] $\cdot \mathrm{C}_{n}, \mathbf{A}-\mathbf{1}$ to $\mathbf{A - 1 9}$; [cefepime] $\cdot \mathrm{C}_{n}$, B-1 to B-19; [cephalexin]. $\mathrm{C}_{n}, \mathbf{C}-1$ to $\mathbf{C - 1 9}$; [cefotaxime] $\mathrm{C}_{n}$, D-1 to D-19; [cefoperazone] $\mathrm{C}_{n}, \mathbf{E}-1$ to $\mathbf{E - 1 9}$ and [ceftriaxone] $\mathrm{C}_{n}, \mathbf{F}-\mathbf{1}$ to $\mathbf{F}-\mathbf{1 9}$ (complexes $\mathbf{7 - 6 0}$ ) are reported in the appropriate tables. Figure 1 depicts the structures of cefadroxil, cefepime, cephalexin, cefotaxime, cefoperazone and ceftriaxone as well as fullerenes $\mathrm{C}_{n}$ ( $n=60,70,76,82$ and 86). The fullerenes and cephalosporin antibiotics were combined to create [cefadroxil] $\cdot \mathrm{C}_{n}$, A-1 to A-5; [cefepime] $\mathbf{C}_{n}, \mathbf{B}-\mathbf{1}$ to B-5; [cephalexin] $\mathrm{C}_{n}, \mathbf{C}$ 1 to C-5; [cefotaxime] $\cdot \mathrm{C}_{n}$, D-1 to D-5; [cefoperazone] $\cdot \mathrm{C}_{n}$, E-1 to E-5 and [ceftriaxone] $\mathrm{C}_{n}, \mathbf{F}-\mathbf{1}$ to $\mathbf{F - 5}$.

Figures 2a, d have shown the relationships between the number of carbon atoms $(n)$ in the fullerenes and the first to fourth free-energies of electron transfer $\left(\Delta G_{\mathrm{et}(1)}-\Delta G_{\mathrm{et}(4)}\right)$ of [cefadroxil] $\cdot \mathrm{C}_{n}(n=60,70,76,82$ and 86$)$. Equations $4-7$ correspond to Fig. 2a, d. This data were fitted with a second-order polynomial equation. The R-squared values $\left(R^{2}\right)$ for these graphs are $0.9875,0.9923,0.9384$ and 0.9478 , respectively.

Equations 4-7 can be utilized to calculate the values of $\Delta G_{\mathrm{et}(1)}-\Delta G_{\mathrm{et}(4)}$ of [cefadroxil] $\cdot \mathrm{C}_{n}$. Table 1 contains the calculated values of the free energies of electron transfer $\left(\Delta G_{\text {et }(n)}, n=1-4\right)$ between the selected cefadroxil and $\mathrm{C}_{n}$ (as [cefadroxil] $\cdot \mathrm{C}_{n}$ compounds $\mathbf{A - 1}$ to $\mathbf{A - 5}$ ) 7-11 
supramolecular complexes. The $\Delta G_{\mathrm{et}(n)}(n=1-4)$ for [cefadroxil]. $\mathrm{C}_{n}\left(\mathrm{C}_{60}, \mathrm{C}_{70}, \mathrm{C}_{76}, \mathrm{C}_{82}, \mathrm{C}_{86}, \mathrm{C}_{78}, \mathrm{C}_{84}\right.$ and $\left.\mathrm{C}_{120}\right)$ are predicted using Eqs. 4-7 and the Rehm-Weller equation (see Table 1).

Equations 8-11 have shown the relationships between the number of carbon atoms in the fullerenes and the first to fourth free energies of electron transfer $\left(\Delta G_{\mathrm{et}(1)}-\Delta G_{\mathrm{et}(4)}\right)$ of [cefepime] $\cdot \mathrm{C}_{n}(n=$ selected fullerenes $)$. These data were fitted with a second-order polynomial equation. The $R^{2}$ values for these graphs are $0.9875,0.9924,0.9384$ and 0.9478 , respectively.

Using Eqs. 1 and 8-11, the $\Delta G_{\mathrm{et}(1)}-\Delta G_{\mathrm{et}(4)}$ values of [cefepime]. $\mathrm{C}_{n}$ can be calculated. Table 2 involves the calculated values of the free energies of electron transfer $\left(\Delta G_{\mathrm{et}(n)}, n=1-4\right)$ between cefepime and the $\mathrm{C}_{n}$ (as [cefepime] $\cdot \mathrm{C}_{n}$ compounds $\mathbf{B}-\mathbf{1}$ to $\left.\mathbf{B}-5\right)$ 12-16 supramolecular complexes. The $\Delta G_{\mathrm{et}(n)}(n=1-4)$ for [cefepime] $\mathrm{C}_{n}\left(\mathrm{C}_{60}\right.$, $\mathrm{C}_{70}, \mathrm{C}_{76}, \mathrm{C}_{82}, \mathrm{C}_{86}, \mathrm{C}_{78}, \mathrm{C}_{84}$ and $\mathrm{C}_{120}$ ) have predicted using Eqs. 8-11 and the Rehm-Weller equation (see Table 2).

The results of Rehm-Weller equation have demonstrated the free energies of electron transfer $\left(\Delta G_{\mathrm{et}(n)}\right.$, $n=1-4)$ between cephalexin and the selected fullerenes. Equations 12-15 have shown the relationships between the number of carbon atoms of the fullerenes and the first to fourth free energies of electron transfer of [cephalexin] $\mathrm{C}_{n}(n=60,70,76,82$ and 86$)$. These data were fit with a second-order polynomial. The $R^{2}$ values for these graphs are $0.9885,0.9924,0.9387$ and 0.9478 , respectively.

Using Eqs. 12-15, the values of $\Delta G_{\mathrm{et}(1)}-\Delta G_{\mathrm{et}(4)}$ of [cephalexin]. $\mathrm{C}_{n}$ can be calculated. Table 3 contains the calculated values of the free energies of electron transfer $\left(\Delta G_{\mathrm{et}(n)}, n=1-4\right)$ between the cephalexin and the fullerenes (as [Cephalexin]. $\mathbf{C}_{n} \mathbf{C}-\mathbf{1}$ to $\left.\mathbf{C}-\mathbf{5}\right)$ 17-21 supramolecular complexes. The $\Delta \mathrm{G}_{\mathrm{et}(n)}(n=1-4)$ for [cephalexin]. $\mathrm{C}_{n}$ $\left(\mathrm{C}_{60}, \mathrm{C}_{70}, \mathrm{C}_{76}, \mathrm{C}_{82}, \mathrm{C}_{86}, \mathrm{C}_{78}, \mathrm{C}_{84}\right.$ and $\left.\mathrm{C}_{120}\right)$ are predicted using Eqs. 12-15 and the Rehm-Weller equation (see Table 3).

Equations 16-19 have shown the relationships between the number of carbon atoms in the selected fullerenes and the $\Delta G_{\text {et }(1)}-\Delta G_{\text {et( } 4)}$ values of [cefotaxime]. $C_{n}(n=$ selected fullerenes). These data were fitted with a second-order polynomial equation. The $R^{2}$ values for these graphs are $0.9876,0.9923,0.9386$ and 0.9476 , respectively.

Using Eqs. 1 and 16-19, the values of $\Delta G_{\mathrm{et}(1)}-\Delta G_{\mathrm{et}(4)}$ of [cefotaxime] $\cdot \mathrm{C}_{n}$ can be calculated. Table 4 contains the 76 calculated values of the free energies of electron transfer $\left(\Delta G_{\mathrm{et}(n)}, n=1-4\right)$ between the cefotaxime and the fullerenes (as [cefotaxime] $\mathrm{C}_{n}$, compounds D-1 to D-5) 22-26 supramolecular complexes. The $\Delta G_{\mathrm{et}(n)}(n=1-4)$ for [cefotaxime] $\mathrm{C}_{n}\left(\mathrm{C}_{60}, \mathrm{C}_{70}, \mathrm{C}_{76}, \mathrm{C}_{82}, \mathrm{C}_{86}, \mathrm{C}_{78}, \mathrm{C}_{84}\right.$ and $\mathrm{C}_{120}$ ) are predicted using Eqs. 16-19 and the Rehm-Weller equation (see Table 4).
Equations 20-23 demonstrate the relationships between the number of carbon atoms in the fullerenes and the first, second, third and fourth free-energies of electron transfer $\left(\Delta G_{\mathrm{et}(1)}-\Delta G_{\mathrm{et}(4)}\right)$ of [cefoperazone] $\cdot \mathrm{C}_{n}$ and [ceftriaxone] $\mathrm{C}_{n}$ ( $n=60,70,76,82$ and 86). These data were fitted with a second-order polynomial equation. The $R^{2}$ values for these graphs are: 0.9874, 0.9924, 0.9386 and 0.9478, respectively.

Using Eqs. 1 and 20-23, the values of $\Delta G_{\text {et(1) }}$ to $\Delta G_{\text {et(4) }}$ of [Cefoperazone] $\cdot \mathrm{C}_{n}$ and [Ceftriaxone] $\cdot \mathrm{C}_{n}$ can be calculated. Table 5 contains the calculated values of the free energies of electron transfer $\left(\Delta G_{\mathrm{et}(n)}, n=1-4\right)$ between cefoperazone and ceftriaxone with the fullerenes (as [cefoperazone] $\cdot \mathrm{C}_{n}$ compounds $\mathbf{E}-\mathbf{1}$ to $\mathbf{E}-5$ and [ceftriaxone] $\cdot \mathrm{C}_{n}$ compounds F-1 to F-5) 27-31 and 32-36 complexes, respectively. The $\Delta G_{\mathrm{et}(n)}(n=1-4)$ for [cefoperazone] $\cdot \mathrm{C}_{n}$ and [ceftriaxone] $\cdot \mathrm{C}_{n}\left(\mathrm{C}_{60}, \mathrm{C}_{70}, \mathrm{C}_{76}, \mathrm{C}_{82}, \mathrm{C}_{86}, \mathrm{C}_{78}, \mathrm{C}_{84}\right.$ and $\mathrm{C}_{120}$ ) are predicted using Eqs. 8-11 and the Rehm-Weller equation (see Table 5).

Equations 4-23

\begin{tabular}{|c|c|}
\hline Equation No. & $\Delta G_{\mathrm{et}(n)}=a(n)^{2}+b(n)+c$ \\
\hline 4 & $\Delta G_{\mathrm{et}(1)}=-0.0235(n)^{2}+2.9201(n)-38.8596$ \\
\hline 5 & $\Delta G_{\mathrm{et}(2)}=-0.0280(n)^{2}+3.4983(n)-48.3526$ \\
\hline 6 & $\Delta G_{\mathrm{et}(3)}=-0.0025(n)^{2}+0.0125(n)+79.4105$ \\
\hline 7 & $\Delta G_{\mathrm{et}(4)}=-0.0038(n)^{2}+0.1064(n)+89.1088$ \\
\hline 8 & $\Delta G_{\mathrm{et}(1)}=-0.0235(n)^{2}+2.9201(n)-39.7796$ \\
\hline 9 & $\Delta G_{\mathrm{et}(2)}=-0.0280(n)^{2}+3.4988(n)-49.3125$ \\
\hline 10 & $\Delta G_{\mathrm{et}(3)}=-0.0025(n)^{2}+0.0125(n)+78.4905$ \\
\hline 11 & $\Delta G_{\mathrm{et}(4)}=-0.0038(n)^{2}+0.1064(n)+88.1888$ \\
\hline 12 & $\Delta G_{\mathrm{et}(1)}=-0.0225(n)^{2}+2.7732(n)-46.2585$ \\
\hline 13 & $\Delta G_{\mathrm{et}(2)}=-0.0281(n)^{2}+3.5028(n)-61.6624$ \\
\hline 14 & $\Delta G_{\mathrm{et}(3)}=-0.0026(n)^{2}+0.0259(n)+65.7913$ \\
\hline 15 & $\Delta G_{\mathrm{et}(4)}=-0.0038(n)^{2}+0.1064(n)+75.9688$ \\
\hline 16 & $\Delta G_{\mathrm{et}(1)}=-0.0235(n)^{2}+2.9197(n)-41.8287$ \\
\hline 17 & $\Delta G_{\mathrm{et}(2)}=-0.0280(n)^{2}+3.4983(n)-51.3526$ \\
\hline 18 & $\Delta G_{\mathrm{et}(3)}=-0.0025(n)^{2}+0.0076(n)+76.6012$ \\
\hline 19 & $\Delta G_{\mathrm{et}(4)}=-0.0039(n)^{2}+0.1112(n)+85.9282$ \\
\hline 20 & $\Delta G_{\mathrm{et}(1)}=-0.0235(n)^{2}+2.9196(n)-41.1378$ \\
\hline 21 & $\Delta G_{\mathrm{et}(2)}=-0.0281(n)^{2}+3.5028(n)-50.8224$ \\
\hline 22 & $\Delta G_{\mathrm{et}(3)}=-0.0025(n)^{2}+0.0036(n)+77.4210$ \\
\hline 23 & $\Delta G_{\mathrm{et}(4)}=-0.0038(n)^{2}+0.1064(n)+86.8088$ \\
\hline
\end{tabular}

By application of these results (Eqs. 4-23) and the Rehm-Weller equation, the electron transfer energies $\left(\Delta G_{\text {et }(n)}, n=1-4\right)$ of the complexes formed by the selected cephalosporin antibiotics and fullerenes $\left(\mathrm{C}_{60}, \mathrm{C}_{70}, \mathrm{C}_{76}, \mathrm{C}_{82}\right.$, $\mathrm{C}_{86}, \mathrm{C}_{78}, \mathrm{C}_{84}$ and $\mathrm{C}_{120}$ ) were approximated. The calculated values of the free electron transfer energies $\left(\Delta G_{\mathrm{et}(n)}\right.$, 
$n=1-4)$ for the selected [cephalosporin antibiotics 1-6]. $C_{n}(n=60,70,76,82$ and 86, compounds 7-60) are shown in Tables 1, 2, 3, 4 and 5. The calculated and the predicted values agreed with good approximation. In lieu of increasing the number of carbons atoms $(n)$ in the selected fullerene structures, the values of $\Delta G_{\mathrm{et}(n)}$ $(n=1-4)$ have decreased. Electron transfer (ET) appears to increase with the electron population in the $C_{n}$ structures (see Tables 1, 2, 3, 4, 5). These results may be related to the HOMO-LUMO gaps of the fullerenes. The tables have also shown that some of the $\Delta G_{\operatorname{et}(n)}(n=1-4)$ values of the complexes are negative.

Tables 6, 7, 8, 9 and 10 show the calculated values of the first to fourth free activation energies of electron transfer and the kinetic rate constants of the electron transfers by utilizing Eqs. 2 and 3 for 7-60 in accordance with the Marcus theory. Figure 3 shows the surfaces of the free energies of electron transfer between cefadroxil, cefepime, cephalexin, cefotaxime and cefoperazone and ceftriaxone and the fullerenes ( $n=60,70,76,82$ and 86). The values of the first to fourth activated free energies of electron transfer for 7-60 increase with increasing $\Delta G_{\operatorname{et}(n)}$ and the number of carbon atoms in the complexes, while the kinetic rate constants of electron transfer decrease with increasing $\Delta G_{\mathrm{et}(n)}$ and $\Delta G_{\mathrm{et}(n)}^{\#}(n=1-4)$ for 7-60. The zero values mean that there was not any electron transfer process between those parts of the predicted complexes (see Tables 6, 7, 8, 9, 10; Fig. 3).

By using Eq. 1 (Rehm-Weller equation), Eqs. 2 and 3 (Marcus theory) and Eqs. 4-23, the values of $\Delta G_{\text {et }(n)}$ $(n=1-4), \Delta G_{\text {et } n)}^{\#}$ and $\lambda_{(\mathrm{n})}(n=1-4)$ were calculated for $7-$ 60. The values of the number of carbon atoms (n) show a good relationship with $\Delta G_{\mathrm{et}(n)}(n=1-4), \Delta G_{\mathrm{et}(n)}^{\#}$ and $k_{\mathrm{et}(n)}$ $(n=1-4)$ for all of the cephalosporin-fullerene complexes. Figure 3 shows the surfaces of the free energies of electron transfer $\Delta G_{\mathrm{et}(n)}$ and $\Delta G_{\mathrm{et}(n)}^{\#}(n=1-4)$ between $\mathbf{1}$ and $\mathbf{5}$ and the fullerenes $\left(\mathrm{C}_{60}, \mathrm{C}_{70}, \mathrm{C}_{76}, \mathrm{C}_{82}, \mathrm{C}_{86}, \mathrm{C}_{78}, \mathrm{C}_{84}\right.$ and $\left.\mathrm{C}_{120}\right)$

Table 6 The values of the first to forth free activation energies of electron transfer and the wavelengths of the photoelectron transfer process, $\Delta G_{\mathrm{et}(n)}^{\#}$ (in kcal mol$\left.{ }^{-1}, n-1-4\right)$ and $\lambda_{\mathrm{et}(\mathrm{n})}(\mathrm{nm}, n=1-4)$, respectively, of [Cefadroxil] $\mathrm{C}_{n}$ supramolecular complexes (7-11 and 37-40) supramolecular complexes

\begin{tabular}{|c|c|c|c|c|c|c|c|c|c|}
\hline Id. & {$\left[\right.$ Cefadroxil] $\cdot \mathrm{C}_{n}$} & $\Delta G_{\mathrm{et}(1)}^{\#}$ & $\lambda_{\mathrm{et}(1)}$ & $\Delta G_{\mathrm{et}(2)}^{\#}$ & $\lambda_{\mathrm{et}(2)}$ & $\Delta G_{\mathrm{et}(3)}^{\#}$ & $\lambda_{\mathrm{et}(3)}$ & $\Delta G_{\mathrm{et}(4)}^{\#}$ & $\lambda_{\mathrm{et}(4)}$ \\
\hline 7 & [Cefadroxil]. $\mathrm{C}_{60}$ & 100.43 & 285 & 131.46 & 217 & 173.52 & 165 & 222.59 & 128 \\
\hline 8 & [Cefadroxil].C $\mathrm{C}_{70}$ & 98.17 & 291 & 129.73 & 220 & 165.63 & 173 & 210.29 & 136 \\
\hline 9 & [Cefadroxil].C 76 & 87.21 & 328 & 111.38 & 257 & 151.3 & 189 & 191.99 & 149 \\
\hline 10 & [Cefadroxil]. $C_{82}$ & 70.4 & 406 & 94.46 & 303 & 138.5 & 206 & 172.53 & 166 \\
\hline 11 & [Cefadroxil].C $\mathrm{C}_{86}$ & 63.55 & 450 & 80.96 & 353 & 140.28 & 204 & 174.52 & 164 \\
\hline 37 & [Cefadroxil].C $\mathrm{C}_{78}$ & 82.33 & 347 & 109.19 & 262 & 149.49 & 191 & 188.31 & 152 \\
\hline 38 & [Cefadroxil]. $\mathrm{C}_{84}$ & 67.18 & 426 & 88.85 & 322 & 140.09 & 204 & 174.65 & 164 \\
\hline 39 & [Cefadroxil].C $\mathrm{C}_{96}$ & 31.45 & 909 & 40.75 & 702 & 120.23 & 238 & 145.60 & 196 \\
\hline 40 & [Cefadroxil]. $\mathrm{C}_{120}$ & 8.47 & 3,376 & 13.57 & 2,107 & 78.55 & 364 & 85.11 & 336 \\
\hline
\end{tabular}

The data of $\Delta G_{\mathrm{et}(n)}^{\#}$ (in kcal mol$\left.{ }^{-1}, n-1-4\right)$ and $\lambda_{\mathrm{et}}\left(\mathrm{s}^{-1}, n=1-4\right)$ for [Cefadroxil] $\mathrm{C}_{n}$ supramolecular complexes (7-11 and 37-40)

Table 7 The values of the first to forth free activation energies of electron transfer the wavelengths of the photoelectron transfer process, $\Delta G_{\mathrm{et}(n)}^{\#}$ (in kcal mol$\left.{ }^{-1}, n-1-4\right)$ and $\lambda_{\mathrm{et}(n)}(\mathrm{nm}, n=1-4)$, respectively, of [Cefepime] $\mathrm{C}_{n}$ supramolecular complexes (12-16 and 41-44) supramolecular complexes

\begin{tabular}{|c|c|c|c|c|c|c|c|c|c|}
\hline Id. & {$[$ Cefepime $] \cdot \mathrm{C}_{n}$} & $\Delta G_{\mathrm{et}(1)}^{\#}$ & $\lambda_{\mathrm{et}(1)}$ & $\Delta G_{\mathrm{et}(2)}^{\#}$ & $\lambda_{\mathrm{et}(2)}$ & $\Delta G_{\mathrm{et}(3)}^{\#}$ & $\lambda_{\mathrm{et}(3)}$ & $\Delta G_{\mathrm{et}(4)}^{\#}$ & $\lambda_{\mathrm{et}(4)}$ \\
\hline 12 & {$\left[\right.$ Cefepime].C $\mathrm{C}_{60}$} & 97.42 & 293 & 127.97 & 223 & 169.55 & 169 & 218.09 & 131 \\
\hline 13 & [Cefepime].C $\mathrm{C}_{70}$ & 95.19 & 300 & 126.26 & 226 & 161.76 & 177 & 205.92 & 139 \\
\hline 14 & [Cefepime].C $\mathrm{C}_{76}$ & 84.4 & 339 & 108.2 & 264 & 147.59 & 194 & 187.81 & 152 \\
\hline 15 & [Cefepime].C 82 & 67.88 & 421 & 91.53 & 312 & 134.95 & 212 & 168.57 & 170 \\
\hline 16 & [Cefepime].C $\mathrm{C}_{86}$ & 61.16 & 467 & 78.26 & 365 & 136.72 & 209 & 170.54 & 168 \\
\hline 41 & [Cefepime].C $\mathrm{C}_{78}$ & 79.66 & 359 & 106.12 & 269 & 145.88 & 196 & 184.27 & 155 \\
\hline 42 & [Cefepime].C 84 & 64.77 & 441 & 86.07 & 332 & 136.6 & 209 & 170.76 & 167 \\
\hline 43 & [Cefepime].C $\mathrm{C}_{96}$ & 29.81 & 959 & 38.88 & 735 & 117 & 244 & 142.04 & 201 \\
\hline 44 & [Cefepime].C $\mathrm{C}_{120}$ & 9.35 & 3,058 & 14.68 & 1,948 & 75.94 & 377 & 82.39 & 347 \\
\hline
\end{tabular}

The data of $\Delta G_{\mathrm{et}(n)}^{\#}$ (in kcal mol$\left.{ }^{-1}, n-1-4\right)$ and $\lambda_{\mathrm{et}}\left(\mathrm{s}^{-1}, n=1-4\right)$ for [Cefepime] $\mathrm{C}_{n}$ supramolecular complexes (12-16 and 41-44) 
Table 8 The values of the first to forth free activation energies of electron transfer and the wavelengths of the photoelectron transfer process, $\Delta G_{\mathrm{et}(n)}^{\#}$ (in kcal mol$\left.{ }^{-1}, n-1-4\right)$ and $\lambda_{\mathrm{et}(n)}(\mathrm{nm}, n=1-4)$, respectively, of [Cephalexin] $\cdot \mathrm{C}_{n}$ supramolecular complexes (17-21 and 45-48) supramolecular complexes

\begin{tabular}{|c|c|c|c|c|c|c|c|c|c|}
\hline Id. & {$\left[\right.$ Cephalexin] $\cdot \mathrm{C}_{n}$} & $\Delta G_{\mathrm{et}(1)}^{\#}$ & $\lambda_{\mathrm{et}(1)}$ & $\Delta G_{\mathrm{et}(2)}^{\#}$ & $\lambda_{\operatorname{et}(2)}$ & $\Delta G_{\mathrm{et}(3)}^{\#}$ & $\lambda_{\mathrm{et}(3)}$ & $\Delta G_{\mathrm{et}(4)}^{\#}$ & $\lambda_{\mathrm{et}(4)}$ \\
\hline 17 & [Cephalexin]. $\mathrm{C}_{60}$ & 62.53 & 457 & 86.5 & 331 & 121.21 & 236 & 162.72 & 176 \\
\hline 18 & [Cephalexin]. $\mathrm{C}_{70}$ & 59.98 & 477 & 85.1 & 336 & 114.63 & 249 & 152.23 & 188 \\
\hline 19 & [Cephalexin]. $\mathrm{C}_{76}$ & 51.48 & 555 & 70.4 & 406 & 102.86 & 278 & 136.72 & 209 \\
\hline 20 & [Cephalexin]. $C_{82}$ & 38.75 & 738 & 57.06 & 501 & 92.26 & 310 & 120.38 & 238 \\
\hline 21 & [Cephalexin]. $\mathrm{C}_{86}$ & 33.74 & 847 & 46.69 & 612 & 93.72 & 305 & 122.04 & 234 \\
\hline 45 & [Cephalexin]. $\mathrm{C}_{78}$ & 48.02 & 595 & 66.58 & 429 & 101.39 & 282 & 133.77 & 214 \\
\hline 46 & [Cephalexin]. $C_{84}$ & 36.79 & 777 & 50.71 & 564 & 93.66 & 305 & 122.3 & 234 \\
\hline 47 & [Cephalexin].C 96 & 12.51 & 2,285 & 16.34 & 1,750 & 77.44 & 369 & 98.20 & 291 \\
\hline 48 & [Cephalexin].C 120 & 22.29 & 1,283 & 37.34 & 766 & 44.56 & 641 & 49.96 & 572 \\
\hline
\end{tabular}

The data of $\Delta G_{\mathrm{et}(n)}^{\#}$ (in kcal mol $\left.{ }^{-1}, n-1-4\right)$ and $\lambda_{\mathrm{et}}\left(\mathrm{s}^{-1}, n=1-4\right)$ for [Cephalexin] $\mathrm{C}_{n}$ supramolecular complexes (17-21 and 65-78)

Table 9 The values of the first to forth free activation energies of electron transfer and the wavelengths of the photoelectron transfer process, $\Delta G_{\mathrm{et}(n)}^{\#}$ (in kcal mol$\left.{ }^{-1}, n-1-4\right)$ and $\lambda_{\mathrm{et}(\mathrm{n})}(\mathrm{nm}, n=1-4)$, respectively, of [Cefotaxime] $\mathrm{C}_{n}$ supramolecular complexes (22-26 and 49-52) supramolecular complexes

\begin{tabular}{|c|c|c|c|c|c|c|c|c|c|}
\hline Id. & {$[$ Cefotaxime $] \cdot \mathrm{C}_{n}$} & $\Delta G_{\mathrm{et}(1)}^{\#}$ & $\lambda_{\text {et(1) }}$ & $\Delta G_{\mathrm{et}(2)}^{\#}$ & $\lambda_{\mathrm{et}(2)}$ & $\Delta G_{\mathrm{et}(3)}^{\#}$ & $\lambda_{\mathrm{et}(3)}$ & $\Delta G_{\mathrm{et}(4)}^{\#}$ & $\lambda_{\mathrm{et}(4)}$ \\
\hline 22 & [Cefotaxime]. $\mathrm{C}_{60}$ & 90.81 & 315 & 120.38 & 238 & 160.8 & 178 & 208.1 & 137 \\
\hline 23 & [Cefotaxime]. $\mathrm{C}_{70}$ & 88.63 & 323 & 118.72 & 241 & 153.16 & 187 & 196.25 & 146 \\
\hline 24 & [Cefotaxime]. $\mathrm{C}_{76}$ & 78.26 & 365 & 101.2 & 283 & 139.39 & 205 & 178.59 & 160 \\
\hline 25 & [Cefotaxime].C $\mathrm{C}_{82}$ & 62.35 & 459 & 85.1 & 336 & 127.12 & 225 & 159.84 & 179 \\
\hline 26 & [Cefotaxime]. $\mathrm{C}_{86}$ & 55.92 & 511 & 72.32 & 395 & 128.83 & 222 & 161.76 & 177 \\
\hline 49 & {$\left[\right.$ Cefotaxime]. $\mathrm{C}_{78}$} & 73.88 & 387 & 99.11 & 288 & 137.66 & 208 & 175.02 & 163 \\
\hline 50 & [Cefotaxime].C $\mathrm{C}_{84}$ & 59.59 & 480 & 79.78 & 358 & 128.65 & 222 & 161.87 & 177 \\
\hline 51 & {$\left[\right.$ Cefotaxime].C $\mathrm{C}_{96}$} & 26.32 & 1,086 & 34.69 & 824 & 109.65 & 261 & 133.92 & 213 \\
\hline 52 & [Cefotaxime $]. \mathrm{C}_{120}$ & 11.47 & 2,493 & 17.45 & 1,638 & 70.18 & 407 & 76.14 & 376 \\
\hline
\end{tabular}

The data of $\Delta G_{\mathrm{et}(n)}^{\#}$ (in $\left.\mathrm{kcal} \mathrm{mol}{ }^{-1}, n-1-4\right)$ and $\lambda_{\mathrm{et}}\left(\mathrm{s}^{-1}, n=1-4\right)$ for [Cefotaxime] $\mathrm{C}_{n}$ supramolecular complexes (22-26 and 49-52)

Table 10 The values of the first to forth free activation energies of electron transfer and the wavelengths of the photoelectron transfer process, $\Delta G_{\mathrm{et}(n)}^{\#}$ (in kcal mol$\left.{ }^{-1}, n-1-4\right)$ and $\lambda_{\mathrm{et}(n)}(\mathrm{nm}, n=1-4)$, respectively, of Cefoperazone] $\mathrm{C}_{n}\left(\mathbf{2 7 - 3 1}\right.$ and 53-56) and [Ceftriaxone] $\mathrm{C}_{n}$, (32-36 and 57-60) supramolecular complexes

\begin{tabular}{|c|c|c|c|c|c|c|c|c|c|c|c|}
\hline Id. & {$[\mathrm{CFO}] \cdot \mathrm{C}_{n}$} & Id. & {$[\mathrm{ROC}] \cdot \mathrm{C}_{n}$} & $\Delta G_{\mathrm{et}(1)}^{\#}$ & $\lambda_{\mathrm{et}(1)}$ & $\Delta G_{\mathrm{et}(2)}^{\#}$ & $\lambda_{\mathrm{et}(2)}$ & $\Delta G_{\mathrm{et}(3)}^{\#}$ & $\lambda_{\mathrm{et}(3)}$ & $\Delta G_{\mathrm{et}(4)}^{\#}$ & $\lambda_{\mathrm{et}(4)}$ \\
\hline 27 & {$[\mathrm{CFO}] . \mathrm{C}_{60}$} & 32 & {$[\mathrm{ROC}] \cdot \mathrm{C}_{60}$} & 92.99 & 307 & 122.88 & 233 & 163.69 & 175 & 211.44 & 135 \\
\hline 28 & {$[\mathrm{CFO}] . \mathrm{C}_{70}$} & 33 & {$[\mathrm{ROC}] . \mathrm{C}_{70}$} & 90.81 & 315 & 121.21 & 236 & 155.99 & 183 & 199.45 & 143 \\
\hline 29 & {$[\mathrm{CFO}] . \mathrm{C}_{76}$} & 34 & {$[\mathrm{ROC}] . \mathrm{C}_{76}$} & 80.28 & 356 & 103.53 & 276 & 142.08 & 201 & 181.64 & 157 \\
\hline 30 & {$[\mathrm{CFO}] . \mathrm{C}_{82}$} & 35 & {$[\mathrm{ROC}] . \mathrm{C}_{82}$} & 64.16 & 446 & 87.21 & 328 & 129.73 & 220 & 162.72 & 176 \\
\hline 31 & {$[\mathrm{CFO}] . \mathrm{C}_{86}$} & 36 & {$[\mathrm{ROC}] . \mathrm{C}_{86}$} & 57.66 & 496 & 74.26 & 385 & 131.46 & 217 & 164.66 & 174 \\
\hline 53 & {$[\mathrm{CFO}] . \mathrm{C}_{78}$} & 57 & {$[\mathrm{ROC}] . \mathrm{C}_{78}$} & 75.89 & 377 & 99.09 & 289 & 140.28 & 204 & 178.05 & 161 \\
\hline 54 & {$[\mathrm{CFO}] . \mathrm{C}_{84}$} & 58 & {$[\mathrm{ROC}] . \mathrm{C}_{84}$} & 61.38 & 466 & 79.48 & 360 & 131.19 & 218 & 164.79 & 174 \\
\hline 55 & {$[\mathrm{CFO}] . \mathrm{C}_{96}$} & 59 & {$[\mathrm{ROC}] . \mathrm{C}_{96}$} & 27.52 & 1,039 & 34.07 & 839 & 112.07 & 255 & 136.60 & 209 \\
\hline 56 & {$[\mathrm{CFO}] . \mathrm{C}_{120}$} & 60 & {$[\mathrm{ROC}] \cdot \mathrm{C}_{120}$} & 10.71 & 2,670 & 18.63 & 1,535 & 72.27 & 396 & 78.26 & 365 \\
\hline
\end{tabular}

The data of $\Delta G_{\mathrm{et}(n)}^{\#}$ (in kcal mol $\left.{ }^{-1}, n-1-4\right)$ and $\lambda_{\mathrm{et}}\left(\mathrm{s}^{-1}, n=1-4\right)$ for Cefoperazone] $\mathrm{C}_{n}\left(\mathbf{2 7}-\mathbf{3 1}\right.$ and 53-56) and [Ceftriaxone] $\mathrm{C}_{n},(\mathbf{3 2}-\mathbf{3 6}$ and 5760) supramolecular complexes. The data of them are equal 


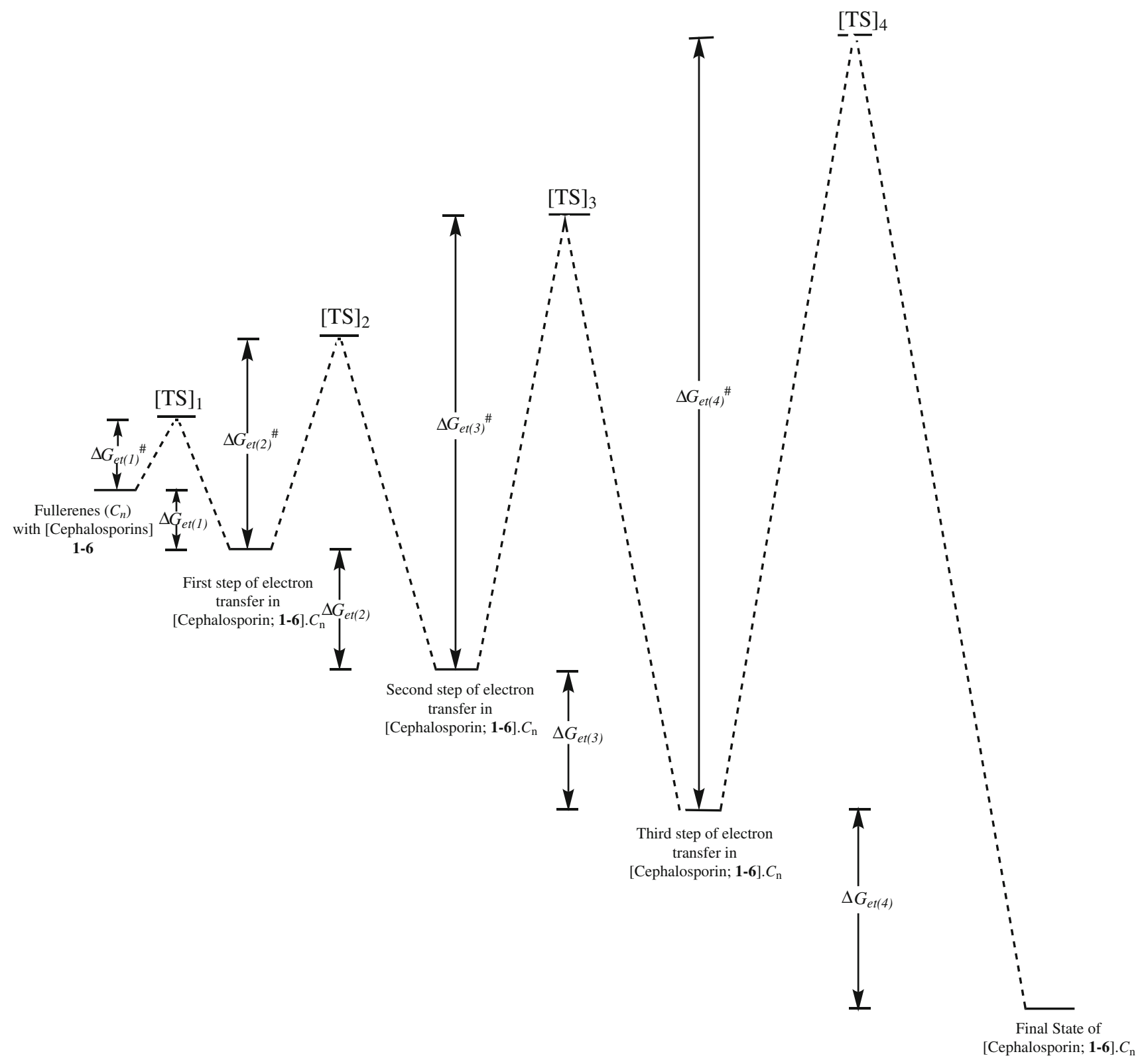

Fig. 3 The surfaces of the free energies of ET-process $\left[\Delta G_{\mathrm{et}(n)}\right.$ and $\left.\Delta G_{\mathrm{et}(n)}^{\#}(n=1-4)\right]$ between $\mathbf{1}$ and $\mathbf{6}$ and fullerenes in 7-60 complexes

for structures 7-60. The free energies were calculated with Eqs. 1-23 and are shown in Tables 1, 2, 3, 4, 5 6, 7, 8, 9 and 10.

We determined the values of the maximum wavelengths $\left(\lambda_{(n)} ; n=1-4\right.$; in $\left.\mathrm{nm}\right)$ for each stage of the electron transfer process in the nanostructure supramolecular complexes with Planck's formula. Using this formula, was also determined the photonic energy of the electron transfer process. Most of the values were found in the UV (200$360 \mathrm{~nm})$ range of the electromagnetic spectrum. The maximum wavelengths $\left(\lambda_{(n)} ; n=1-4\right)$ depended on the $\Delta G_{\mathrm{et}(n)}^{\#}$ value in each stage. The values of the maximum wavelengths $\left(\lambda_{(n)} ; n=1-4\right)$ were increased by decreasing the $\Delta G_{\mathrm{et}(n)}^{\#}$ value in each stage.

In this study, was investigated the photo-electron transfer process to find more medicinal activity properties for the cephalosporin antibiotics 1-6 in the presence of the selected fullerenes by performing the supramolecular complexes [cephalosporin antibiotics 1-6] $\cdot \mathrm{C}_{n}$. The cephalosporin-fullerene supramolecular complexes and the calculated values of $\Delta G_{\mathrm{et}(n)}, \Delta G_{\mathrm{et}(n)}^{\#}$ and $\lambda_{(n)}(n=1-4)$ corresponding to these complexes have not been reported before. 


\section{Conclusion}

In this study, were shown the relationship between the number of carbon atoms and the four free energies of electron transfer $\left(\Delta G_{\mathrm{et}(1)}-\Delta G_{\mathrm{et}(4)}\right)$ of fullerenes $\mathrm{C}_{n}(n=60$, $70,76,82$ and 86) with cefadroxil, cefepime, cephalexin, cefotaxime, cefoperazone and ceftriaxone on the basis of the four reduction potentials ( ${ }^{\text {Red. }} E_{1}-{ }^{\text {Red. }} E_{4}$ ) of the fullerenes. The antibiotics 1-6 and fullerenes have important electron-transfer properties as the most well-known cephalosporin antibiotics ( $\beta$-lactam class of antibiotics) and molecular conductors. The electrochemical data of the cephalosporin-fullerene complexes are reported here. These results include the four free energies of electron transfer $\left(\Delta G_{\mathrm{et}(1)}-\Delta G_{\mathrm{et}(4)}\right)$, calculated using the RehmWeller equation, $\Delta G_{\mathrm{et}(n)}^{\#}$ and $\lambda_{(n)}(n=1-4)$, using the Marcus theory. Using the number of carbon atoms in the fullerene molecules and the model equations, the structural relationships between the aforementioned physicochemical data can be derived. These equations allow one to calculate $\Delta G_{\mathrm{et}(n)}(n=1-4), \Delta G_{\mathrm{et}(n)}^{\#}$ and $\lambda_{(n)}(n=1-4)$ for cephalosporin antibiotics 1-6, as [cefadroxil] $\mathrm{C}_{n} \mathbf{7 - 1 1}$ and 37-40; [cefepime] $\mathrm{C}_{n}, \mathbf{1 2 - 1 6}$ and 41-44; [cephalexin] $\mathrm{C}_{n}, \mathbf{1 7 - 2 1}$ and 45-48; [cefotaxime] $\mathrm{C}_{n}, \mathbf{2 2 - 2 6}$ and 49-52; [cefoperazone] $\cdot \mathrm{C}_{n}, \mathbf{2 7 - 3 1}$ and $\mathbf{5 3}-\mathbf{5 6}$ and [ceftriaxone] $\cdot \mathrm{C}_{n}, \mathbf{3 2}-\mathbf{3 6}$ and 57-60 (supramolecular complexes 7-60) of the fullerenes $\left(\mathrm{C}_{60}, \mathrm{C}_{70}, \mathrm{C}_{76}, \mathrm{C}_{82}, \mathrm{C}_{86}, \mathrm{C}_{78}, \mathrm{C}_{84}\right.$ and $\left.\mathrm{C}_{120}\right)$. One of the other aspects of this study was the investigation of the photo-electron transfer process to find more medicinal activity conditions and properties for the antibiotics 1-6 in the presence of the selected fullerenes by performing the supramolecular complexes [antibiotics 1-6] $\cdot \mathrm{C}_{n}$. The novel supramolecular complexes discussed have neither been synthesized nor reported before.

Acknowledgments The corresponding author gratefully acknowledges his colleagues in the Chemistry Department of The University of New England (UNE)-Australia for their useful suggestions. The authors are grateful to the Medical Biology Research Center, Kermanshah University of Medical Sciences, Kermanshah, Iran and the Research and Computational Lab of Theoretical Chemistry and Nano Structures of Razi University Kermanshah-Iran for supporting this study.

Open Access This article is distributed under the terms of the Creative Commons Attribution License which permits any use, distribution, and reproduction in any medium, provided the original author(s) and the source are credited.

\section{References}

1. Merkt, U., Huser, J., Wagner, M.: Energy spectra of two electrons in a harmonic quantum dot. Phys. Rev. B. 43, 7320-7323 (1991)

2. Pfannkuche, D., Gerhardts, R.R.: Quantum-dot helium: effects of deviations from a parabolic confinement potential. Phys. Rev. B. 44(23), 13132-13135 (1991)
3. Ciftja, O.: Classical behavior of few-electron parabolic quantum dots. Phys. B 404, 2629 (2009)

4. Wagner, M., Merkt, U., Chaplik, A.V.: Spin-singlet-spin-triplet oscillations in quantum dots. Phys. Rev. B. 45, 1951R-1954R (1992)

5. Ciftja, O.: A Jastrow correlation factor for two-dimensional parabolic quantum dots. Mod. Phys. Lett. B 23(26), 3055-3064 (2009)

6. Ciftja, O.: Generalized description of few-electron quantum dots at zero and nonzero magnetic field. J. Phys. Condens. Matter 19, 046220 (2007)

7. Pfannkuche, D., Gerhardts, R.R., Maksym, P.A., Gudmundsson, V.: Theory of quantum dot helium. Phys. B 189(1-4), 6-15 (1993)

8. Takeda, N., Kitagawa, J., Ishikawa, M.: Variational wave function for a two-electron quantum dot. Phys. B 255, 145-149 (1998)

9. Ezaki, T., Mori, N., Hamaguchi, C.: Electronic structures in circular, elliptic, and triangular quantum dots. Phys. Rev. B. 56(11), 6428-6431 (1997)

10. Pfannkuche, D., Gudmundsson, V., Maksym, P.A.: Comparison of a Hartree, a Hartree-Fock, and an exact treatment of quantumdot helium. Phys. Rev. B. 47(4), 2244-2250 (1993)

11. El-Shaboury, S.R., Saleh, G.A., Mohamed, F.A., Rageh, A.H.: Analysis of cephalosporin antibiotics. J. Pharm. Biomed. Anal. 45(1), 1-19 (2007)

12. Sweetman, S.: Martindale, The Extra Pharmacopoeia, 33rd edn, pp. 161-179. Royal Pharmaceutical Society, London (2002)

13. Dollery, C.: Therapeutic Drugs, vol. I, 2nd edn, pp. 83-156. Churchill Livingstone, Edinburgh (1999)

14. Nigamb, P., Mohana, S., Kundub, S., Prakash, P.: Trace analysis of cefotaxime at carbon paste electrode modified with novel schiff base Zn(II) complex. Talanta 77, 1426-1431 (2009)

15. http://www. Wikipedia Cefadroxil-Wikipedia, the free encyclopedia.htm

16. Yahav, D., Paul, M., Fraser, A., Sarid, N., Leibovici, L.: Efficacy and safety of cefepime: a systematic review and meta-analysis. Lancet Infect Dis. 7(5), 338-348 (2007)

17. Chapman, T.M., Perry, C.M.: Cefepime: a review of its use in the management of hospitalized patients with pneumonia. Am. J. Respir. Med. 2(1), 75-107 (2003)

18. Information for healthcare professionals: cefepime (marketed as Maxipime). http://www.fda.gov/Drugs/DrugSafety/PostmarketDrug SafetyInformationforPatientsandProviders/DrugSafetyInformation forHeathcareProfessionals/ucm167254.htm

19. Sneader, W.: Cephalosporin Analogues. Drug Discovery: A History, p. 324. Wiley, New York (2005)

20. Britta, K., Ralf, R.: $\beta$ - lactam antibiotics inhibit chloroplast division in a moss (Physcomitrella patens) but not in tomato (Lycopersicon esculentum). J. Plant Physiol. 150, 137-140 (1997)

21. Stork, C.M.: Antibiotics, antifungals, and antivirals. In: Nelson, L.H., Flomenbaum, N., Goldfrank, L.R., Hoffman, R.L., Howland, M.D., Lewin, N.A. (eds.) Goldfrank's Toxicologic Emergencies, p. 847. McGraw-Hill, New York (2006)

22. Bradley, J.S., Wassel, R.T., Lee, L., Nambiar, S.: Intravenous ceftriaxone and calcium in the neonate: assessing the risk for cardiopulmonary adverse events. Pediatrics 123(4), e609-e613 (2009)

23. Kroto, H.W., Heath, J.R., O'Brien, S.C., Curl, R.F., Smalley, R.F.: $C_{60}$ : Buckminsterfullerene. Nature 318, 162-163 (1985)

24. Kroto, H.W.: The stability of the fullerenes $\mathrm{C}_{n}$, with $n=24,28$, 32, 36, 50, 60 and 70. Nature 329, 529-531 (1987)

25. Shen, H.: The compressive mechanical properties of $\mathrm{C}_{n}(n=20$, $60,80,180)$ and endohedral M@ C60 (M = Na, Al, Fe) fullerene molecules. Mol. Phys. 105(17-18), 2405-2409 (2007) 
26. Kimura, K., Ikeda, N., Maruyama, Y., Okazaki, T., Shinohara, H., Bandow, S., Iijima, S.: Evidence for substantial interaction between Gd ion and SWNT in (Gd@C82)@SWNT peapods revealed by STM studies. Chem. Phys. Lett. 379, 340-344 (2003)

27. Smith, B.W., Monthioux, M., Luzzi, D.E.: Encapsulated C 60 in carbon nanotubes. Nature 396, 323-324 (1998)

28. Miyake, T., Saito, S.: Electronic structure of $\mathrm{C}_{60}$-encapsulating semiconducting carbon nanotube. Solid State Commun. 125, 201-204 (2003)

29. Zhang, M., Yudasaka, M., Bandow, S., Iijima, S.: Thermogravimetric analysis for the array of $\mathrm{C} 60$ molecules formed in single-wall carbon nanotube. Chem. Phys. Lett. 369, 680-683 (2003)

30. Kavan, L., Dunsch, L., Kataura, H.: Electrochemical tuning of electronic structure of carbon nanotubes and fullerene peapods. Carbon 42, 1011-1019 (2004)

31. Sherigara, B.S., Kutner, W., D’Souza, F.: Electrocatalytic properties and sensor applications of fullerenes and carbon nanotubes. Electroanalysis 15, 753-772 (2003)

32. Haufler, R.E., Conceicao, J., Chibante, L.P.F., Chai, Y., Byrne, N.E., Flanagan, S., Haley, M.M., O’Brien, S.C., Pan, C., Xiao, Z., Billups, W.E., Ciufolini, M.A., Hauge, R.H., Margrave, J.L., Wilson, L.J., Curl, R.F., Smalley, R.E.: Efficient production of C60 (Buckminsterfullerene), $\mathrm{C} 0 \mathrm{H}_{36}$, and the solvated buckide ion. J. Phys. Chem. 94, 8634-8636 (1990)

33. Xie, Q., Perez-Codero, E., Echegoyen, L.: Electrochemical detection of $\mathrm{C}^{6} 0^{6-}$ and $\mathrm{C} 70^{6-}$ : enhanced stability of fullerides in solution. J. Am. Chem. Soc. 114, 3978-3980 (1992)

34. Jehoulet, C., Obeng, Y.O., Kim, Y.T., Zhou, F., Bard, A.J.: Electrochemistry and Langmuir trough studies of fullerene $\mathrm{C}_{60}$ and $\mathrm{C}_{70}$ films. J. Am. Chem. Soc. 114(11), 4237-4247 (1992)

35. Janda, P., Krieg, T., Dunsch, L.: Nanostructuring of highly ordered C60 films by charge transfer. Adv. Mater. 17, 1434-1438 (1998)

36. Touzik, A., Hermann, H., Janda, P., Dunsch, L., Wetzig, K.: Nanostructuring of potassium fulleride layers. Europhys. Lett. 60 , 411-417 (2002)

37. Tsuchiya, T., Shimizu, T., Kamigata, N.: Unsaturated thiacrown ethers: synthesis, physical properties, and formation of a silver complex. J. Am. Chem. Soc 123(47), 11534-11538 (2001). (and the literature cited therein)

38. Tsuchiya, T., Kurihara, H., Sato, K., Wakahara, T., Akasaka, T., Shimizu, T., Kamigata, N., Mizorogi, N., Nagase, S.: Supramolecular complexes of La@C82 with unsaturated thiocrown ethers. Chem. Commun 34, 3585-3587 (2006). (and the literature cited therein)

39. Anderson, M.R., Dorn, H.C., Stevenson, S.A.: Making connection between fullerenes and metallofullerenes. Carbon 38, 1663-1670 (2000)

40. Cooper, S.R.: Crown thioether chemistry. Acc. Chem. Res. 21, 141 (1998)

41. Taherpour, A.A.: Quantitative relationship study of mechanical structure properties of empty fullerenes. Fulle. Nanotu. Carb. Nanostruct. 16, 196-205 (2008)

42. Taherpour, A.A., Lajevardi, P.S.: structural relationships and theoretical study of free energies of electron transfer, electrochemical properties, and electron transfer kinetic of $p$-phenylenediamine derivatives with fullerenes in nanostructure $[\mathrm{R}] \cdot \mathrm{C}_{n}$ ( $\mathrm{R}=$ TMPD, DHDMP, TMDAD and DHDAP) supramolecular complexes. Int. J. Electrochem. Sci. 6, 5482-5498 (2011)

43. Taherpour, A.A.: Theoretical and quantitative structural relationship studies of electrochemical properties of the nanostructures of cis-unsaturated thiocrown ethers and their supramolecular complexes [X-UTY][M@ $\left.\mathrm{C}_{82}\right](\mathrm{M}=\mathrm{Ce}, \mathrm{Gd})$. Phos. Sulf. Silic. Rel. Elemen. 185, 422-432 (2010)

44. Du, Y.P., Liang, Y.Z., Li, B.Y., Xu, C.J.: Orthogonalization of block variables by subspace-projection for quantitative structure property relationship (QSPR) research. J. Chem. Inf. Cmput. Sci. 42, 993-1003 (2002)

45. Randić, M.: Characterization of molecular branching. J. Am. Chem. Soc. 97, 6609-6615 (1975)

46. Bolboaca, S.D., Jantschi, L.: How good can the characteristic polynomial be for correlations? Int. J. Mol. Sci. 8, 335-345 (2007)

47. Slanina, Z., Uhlik, F., Lee, S.L., Osawa, E.: Geometrical and thermodynamic approaches to the relative stabilities of fullerene isomers. MATCH Commun. Math. Comput. Chem. 44, 335-348 (2001)

48. Taherpour, A.A., Shafiei, F.: The structural relationship between Randic' indices, adjacency matrixes, distance matrixes and maximum wave length of linear simple conjugated polyene compounds. J. Mol. Struct. THEOCHEM. 726, 183-188 (2005)

49. Taherpour, A.A.: Structural relationship between degree of unsaturation with fermi energy, chemical hardness, and theHOMOLUMOgap of $(5,5)$ armchair single-walled carbon nanotubes. Fulle. Nanotu. Carb. Nanostruct. 17(1), 26-37 (2009)

50. Taherpour, A.A.: Quantitative structural relationship and theoretical study of electrochemical properties of C60@[SWCNT $(5,5)$ armchair-CnH20] complexes. Chem. Phys. Lett. 469, 135-139 (2009)

51. Taherpour, A.A.: Theoretical and quantitative structural relationship study of the electrochemical properties of $\left[\mathrm{M}_{2}\right.$ @ $\mathrm{C}_{x}$ ] $\left[\mathrm{SWCNT}(5,5)\right.$-armchair- $\left.\mathrm{C}_{n} \mathrm{H}_{20}\right](\mathrm{M}=\mathrm{Er}$ and $\mathrm{Sc}, x=82$ and 84 , and $n=20-300$ ) complexes. J. Phys. Chem. C 113(14), 5402-5408 (2009)

52. Slanina, Z., Chao, M.C., Lee, S.L., Gutman, I.: On applicability of the Wiener index to estimate relative stabilities of the higherfullerene IPR isomers. J. Serb. Chem. Soc. 62(3), 211-217 (1997)

53. Plavšić, D., Nikolić, S., Trinajstić, N., Mihalić, Z.: On the Harary index for the characterization of chemical graphs. J. Math. Chem. 12, 235-250 (1993)

54. Rehm, D., Weller, A.: Kinetics of fluorescence quenching by electron and H-atom transfer. Isr. J. Chem. 8, 259-271 (1970)

55. Marcus, R.A.: Electron transfer reactions in chemistry. Theory and experiment. Rev. Mod. Phys. 65, 599 (1993)

56. Marcus, M.A.: Theory for Electron Transfer a short introduction MPIP-Journal Club-Mainz-January 29 (2008)

57. Barbara, P.F., Meyer, T.J., Ratner, M.A.: Contemporary issues in electron transfer research. J. Phys. Chem. 100(31), 13148-13168 (1996)

58. Newton, M.D.: Quantum chemical probes of electron-transfer kinetics: the nature of donor-acceptor interactions. Chem. Rev. 91(5), 767-792 (1991)

59. Freed, K.F., Jortner, J.: Multiphonon processes in the nonradiative decay of large molecules. J. Chem. Phys. 52, 6272-6291 (1970)

60. Marcus, R.A.: On the theory of electron-transfer reactions. VI. Unified treatment for homogeneous and electrode reactions. J. Chem. Phys. 43, 679-701 (1965)

61. Marcus, R.A., Sutin, N.: Electron transfers in chemistry and biology. Biochim. Biophys. Acta 811(3), 265-322 (1985)

62. Kuzmin, M.G., XVIIth IUPAC Symposium on photochemistry, July 22-27, Book of abstracts, p. 372. Dresden, German (2000)

63. Adamowski, J., Sobkowicz, M., Szafran, B., Bednarek, S.: Electron pair in a Gaussian confining potential. Phys. Rev. B. 62(7), 4234-4237 (2000)

64. De Filippo, S., Salerno, M.: Spectral properties of a model potential for quantum dots with smooth boundaries. Phys. Rev. B. 62(7), 4230-4233 (2000)

65. Ciftja, O.: Calculation of the Coulomb electrostatic potential created by a uniformly charged square on its plane: exact mathematical formulas. J. Electrost. 71(2), 102-108 (2013)

66. Stopa, M.: Quantum dot self-consistent electronic structure and the Coulomb blockade. Phys. Rev. B. 54(19), 13767-13783 (1996) 
67. Ciftja, O.: An experimentally justified confining potential for electrons in two-dimensional semiconductor quantum dots. J. Comp-Aided Mater. Des. 14, 37-44 (2007)

68. Bruce, N.A., Maksym, P.A.: Quantum states of interacting electrons in a real quantum dot. Phys. Rev. B. 61(7), 4718-4726 (2000)

69. http://en.wikipedia.org/wiki/Photoinduced_electron_transfer

70. Atkins, P.W.: Physical Chemistry, 6th edn. Oxford University Press, Oxford (1998)

71. Özkan, S.A., Erk, N., Uslu, B., Yilmaz, N., Biryol, I.: Study on electrooxidation of cefadroxil monohydrate and its determination by differential pulse voltammetry. J. Pharm. Biomed. Anal. 23, 263-273 (2000)

72. Özkan, S.A., Uslu, B., Zuman, P.: Electrochemical reduction and oxidation of the antibiotic cefepim on a carbon electrode. Anal. Chim. Acta 457, 265-274 (2002)

73. Chailapakul, O., Fujishima, A., Tipthara, P., Siriwongchai, H.: Electroanalysis of glutathione and cephalexin using the borondoped diamond thin-film electrode applied to flow injection analysis. Anal. Sci. 17, i419-i422 (2001)

74. Devi, A.R., Rani, K.S., Rao, V.S.: Polarographic determination of cephalosporins in pure form and in pharmaceutical preparations. Indian J. Pharm. Sci. 56(2), 64-66 (1994)
75. Chailapakul, O., Aksharanandana, P., Frelink, T., Einaga, Y., Fujishima, A.: The electrooxidation of sulfur-containing compounds at boron-doped diamond electrode. Sens Actuators B. 80, 193-201 (2001)

76. Nigam, P., Mohan, S., Kundu, S., Prakash, R.: Trace analysis of cefotaxime at carbon paste electrode modified with novel Schiff base Zn(II) complex. Talanta 77(4), 1426-1431 (2009)

77. Abo El-Maali, N., Ali, A.M.M., Ghandour, M.A.: Electrochemical reduction and oxidation of two cephalosporin antibiotics; Ceftriaxone (Rocephine) and Cefoperazone (Cefobid). Electroanalysis 5, 599-604 (1993)

78. Abo El-Maali, N., Ghandour, M.A., Kauffmann, J.M.: Cephalosporin antibiotics at bare and modified carbon paste electrodes in both aqueous and biological media. Bioelectrochem Bioenerg. 38, 91-97 (1995)

79. Suzuki, T., Kikuchi, K., Oguri, F., Nakao, Y., Suzuki, S., Achiba, Y., Yamamoto, K., Funasaka, H., Takahashi, T.: Electrochemical properties of fullerenolanthanides. Tetrahedron 52(14), 4973 (1996) 